\title{
A two-gene strategy increases the iron and zinc concentration of wheat flour and improves
} mineral bioaccesibility for human nutrition.

3 Authors: Sophie A Harrington ${ }^{1}$, James M Connorton ${ }^{1,4}$, Natasha I M Nyangoma ${ }^{2}$, Rose McNelly ${ }^{1,4}$, Yvie M L Morgan ${ }^{1,4}$, Mohamad F Aslam³ ${ }^{3}$ Paul A Sharp ${ }^{3}$, Alexander A T Johnson ${ }^{2}$, Cristobal Uauy ${ }^{1}$, Janneke Balk ${ }^{1,4}$

$6 \quad{ }^{1}$ John Innes Centre, Norwich Research Park, Norwich NR4 7UH, UK

$7 \quad{ }^{2}$ School of BioSciences, The University of Melbourne, Victoria 3010, Australia

$8{ }^{3}$ Department of Nutritional Sciences, King's College London, London SE1 9NH, UK

$9 \quad{ }^{4}$ School of Biological Sciences, University of East Anglia, Norwich NR4 7TJ, UK

Correspondence: Janneke Balk, janneke.balk@jic.ac.uk

Author contributions: J.M.C., A.A.T.J., C.U and J.B. conceived the study and the overall research plans. S.A.H., J.M.C., N.I.M.N., R.M., Y.M.L.M. and M.F.A. designed and performed the experiments. All authors analysed the data. S.A.H. and J.B. wrote the article with contributions of all authors.

\section{Abstract}

Dietary deficiencies of iron and zinc cause human malnutrition globally, which can be mitigated by biofortified staple crops. Conventional breeding approaches to increase grain mineral concentrations in wheat (Triticum aestivum L.) have had only limited success so far due to relatively low genetic variation. Here we demonstrate that a transgenic approach combining endosperm-specific expression of the wheat vacuolar iron transporter gene TaVIT2-D with constitutive expression of the rice nicotianamine synthase gene OsNAS2 has the potential to dramatically improve mineral micronutrient intake from wheat products. In two distinct bread wheat cultivars, we show that the VIT-NAS construct led to a two-fold increase in zinc to $\sim 50 \mu \mathrm{g} \mathrm{g}^{-1}$ in wholemeal flour and a two-fold increase in both zinc and iron in hand-milled white flour. In highly pure, roller-milled white flour, the concentration of iron was enhanced three-fold to $\sim 25 \mu \mathrm{g} \mathrm{g}^{-1}$. A greater than three-fold increase in the level of the natural plant metal chelator nicotianamine in the grain of VIT-NAS lines was associated with improved iron and zinc bioaccessibility in white flour. The growth of VIT-NAS plants in the greenhouse was indistinguishable from untransformed controls. We conclude that the effects of each gene cassette are additive in altering the total concentration and distribution of iron and zinc in wheat grains. This demonstrates the potential of a transgenic approach to enhance the nutritional quality of wheat well beyond what is possible by breeding approaches in order to alleviate dietary mineral deficiencies.

Low dietary intake of the essential mineral micronutrients iron and zinc from staple crops contributes to the global burden of malnutrition. Iron deficiency is the leading cause of anaemia worldwide, particularly affecting young children and adult females (1). In children, iron deficiency can lead to stunted development, while in adults it can severely hinder economic productivity and greatly enhances the risk of maternal death in childbirth (2). Zinc deficiency affects all age groups and genders, manifested in stunting and reduced immunity to infectious diseases (3). In some South Asian and subSaharan countries with cereal-dominated diets, over half of the population is predicted to be zincdeficient (4). 
Bread wheat (Triticum aestivum L.) is a global staple which provides between 20 and $25 \%$ of calories worldwide (5). Yet a combination of uneven nutrient distribution and associated anti-nutrient factors within the grain make wheat a suboptimal source of iron and zinc in human diets (6). Iron and zinc are predominantly located in the aleurone tissue and embryo (7-10). These parts of the grain are removed during industrial-scale roller milling of white flour, leading to the loss of $65-75 \%$ of the iron and zinc present in the whole grain $(6,11)$. Additionally, the bran fractions enriched in aleurone, pericarp, and embryo tissues contain high amounts of phytate (myoinositol-1,2,3,4,5,6-hexakisphosphate), an antinutrient which inhibits iron and zinc bioavailability $(12,13)$. Efforts to improve iron and zinc concentrations in wheat, therefore, must deal with the complementary issues of low levels of mineral micronutrient in the starchy endosperm, and low bioavailability in the outer cell layers comprising the bran.

Attempts have been made to leverage natural variation in wheat germplasm to increase grain iron and zinc concentrations by conventional breeding. A recent analysis of mineral micronutrients in the Watkins panel of wheat landraces identified variation of 24 to $49 \mathrm{\mu g} \mathrm{g}^{-1}$ zinc in the wholemeal flour, and 8 to $15 \mu \mathrm{g} \mathrm{g}^{-1}$ zinc in white flour (14). Similar levels of variation in zinc have been found in panels of Indian-adapted wheat varieties and CIMMYT germplasm (15-17). Variation in iron concentrations is also seen within wheat germplasm, particularly landraces and wild relatives; a panel of 170 elite, landrace, and wild relative varieties had wholemeal iron concentrations ranging from 25 to $56 \mu \mathrm{g} \mathrm{g}^{-1}$ iron (18). This existing genetic variation has been used to improve wholegrain micronutrient levels in elite wheat varieties. For example, introgression of the transcription factor NAM-B1 from T. turgidum ssp. dicoccoides into bread wheat led to an increase in iron and zinc content of 18 and $12 \%$, respectively $(19,20)$. However, while genetic variation in the wholegrain iron concentration exists within germplasm stocks, to our knowledge no significant natural variation has been observed for iron in white flour, nor for increased iron bioavailability (21). As a result, research effort has turned towards implementing transgenic and cisgenic approaches to improve iron and zinc levels and their bioavailability $(6,22)$.

Early work towards enhancing micronutrient levels was carried out in rice, exploiting genes involved in iron uptake, transport and storage. NICOTIANAMINE SYNTHASE (NAS), encoding the enzyme that synthesizes the metal chelator nicotianamine (NA), plays a key role in iron uptake and mobility of divalent metal ions in plants (23). Overexpression of either of the three individual NAS genes in rice not only led to increased concentrations of NA, iron, and zinc in rice grains, but also improved iron bioavailability (24-27). An alternative approach to improving grain micronutrient content focussed on the iron storage protein ferritin. Endosperm-specific expression of the soybean FERRITIN gene in rice led to an increase in grain iron concentration by two-to-three fold (28).

Initial efforts to biofortify wheat flour with iron and zinc built on the findings in rice, targeting similar candidate genes. Endosperm-specific expression of a FERRITIN gene from wheat or bean in bread wheat led to a $\sim 60 \%$ increase in total grain iron $(29,30)$, however X-Ray Fluorescence imaging showed that iron accumulated in the crease of the grain, not in the endosperm (31). High expression of the rice OsNAS2 gene in wheat under a constitutive promoter led to $40-100 \%$ more iron and $60-250 \%$ more zinc in whole grains (30). Field trials of wheat lines generated in a different study but with a similar OsNAS2 gene cassette showed increases of up to $30 \%$ more iron and up to $50 \%$ more zinc in whole grain and white flour. Whereas improvements in the mineral micronutrient concentrations varied from year to year and in different field sites, the lines showed a robust $>200 \%$ increase in NA, as well as improved iron bioavailability (32). Another strategy to modify grain iron was demonstrated in wheat by overexpressing the wheat VACUOLAR IRON TRANSPORTER 2 gene (TaVIT2-D) under the wheat endosperm-specific HIGH MOLECULAR WEIGHT GLUTENIN-D1 promoter $(33,34)$. This resulted 
in redistribution of iron to the endosperm region adjacent to the embryo, with a consistent $\sim 200 \%$ increase in iron in hand-milled white flour and $\geq 250 \%$ increase in highly pure, roller-milled white flour fractions, from 8 to $20 \mu \mathrm{g} \mathrm{g}^{-1}(6,33)$.

Here we report on the results of combining endosperm expression of the TaVIT2-D gene with constitutive expression of the OsNAS2 gene in hexaploidy bread wheat. Transformation with the so called VIT-NAS construct in two genetically distinct wheat cultivars led to significant increases in both iron and zinc concentrations in white and wholemeal flour, with additive effects of each gene cassette and minimal impacts on plant growth. NA levels were up to ten-fold higher in the VIT-NAS lines compared to control, correlating with increased iron and zinc bioaccessibility.

\section{RESULTS}

\section{The VIT-NAS construct drives high levels of TaVIT2 and OsNAS2 expression in grain and leaf tissue.}

To increase the total amount of iron and zinc in the wheat grain, while maximizing the concentration in the endosperm, we generated a construct, referred to as VIT-NAS, combining the HMWG::TaVIT2$D$ cassette (33) with the ZmUBI1::OsNAS2 cassette (35) in a binary T-DNA vector with the hygromycin resistance marker (Figure 1A). Transformation of the VIT-NAS construct was independently carried out in both the cultivar Fielder, nowadays only used for research, and the cultivar Gladius, a droughtresistant variety grown in Australia. Following selection for hygromycin resistance, a total of thirteen independent transformants were obtained in cv. Fielder, with copy numbers ranging from one (in two transformants) to more than twelve. Iron staining of grains was used to select five independent transformants alongside a null transformant for further characterisation in homozygous lines of the $\mathrm{T}_{3}$ generation (Table 1). In cv. Gladius, 37 independent transformation events were obtained of which three independent lines with a single insert of the T-DNA- BD1-T, BD4-T, and BD7-T, alongside their null-segregant siblings (NS) - were selected for analysis in the $T_{1}$ generation.

\section{Table 1: VIT-NAS independent transformants in cv. Fielder and controls}

\begin{tabular}{ll}
\hline Line & Copy Number $(2 \mathbf{n})$ \\
\hline A1 & 0 \\
\hline A10 & 2 \\
B4 & 4 \\
B12 & $\sim 12^{\text {a }}$ \\
B14 & 6 \\
B71 & $>20^{a}$ \\
TaVIT2 $^{\text {b }}$ & 8 \\
22-15 & 0 \\
\hline
\end{tabular}

${ }^{a}$ Quantification accuracy declines at high copy numbers.

${ }^{\mathrm{b}} \mathrm{TaVIT2}$ is line 22-19 as described in (33) and 22-15 is a null transformant from the same study.

Expression analysis by RT-qPCR confirmed high levels of TaVIT2-D and OsNAS2 expression in the cV. Fielder VIT-NAS lines compared to the null line A1 (Figure 1B, C). One transformant line, A10, had very low expression of OsNAS2 in both the grain and leaf tissue compared to the other VIT-NAS lines, indicating that the gene is not properly transcribed in this line. The expression of the TaVIT2-D transgene in $\mathrm{A} 10$ is high in the grain and low in leaves, as expected from the endosperm-specific HMWG promoter. Unexpectedly, the other VIT-NAS lines had elevated expression levels of the introduced TaVIT2-D gene in leaf tissue. We speculate this may be due to insertion of several copies 

Discussion).

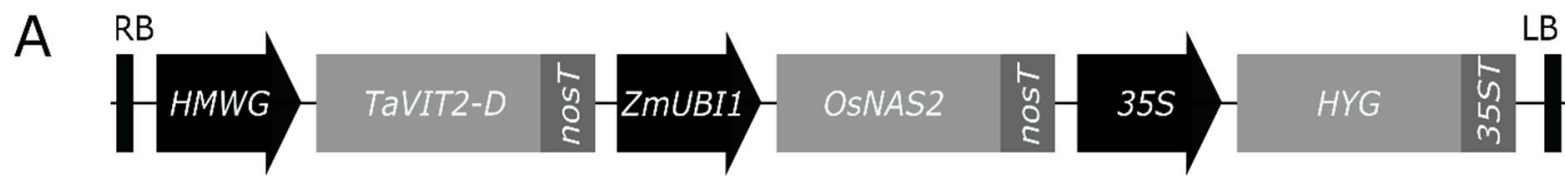

B

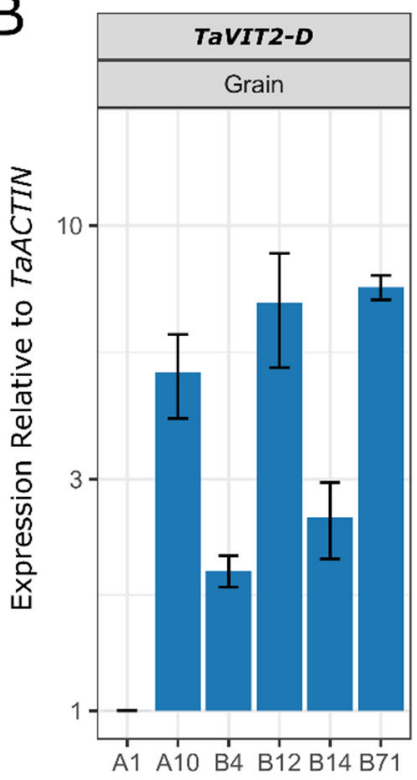

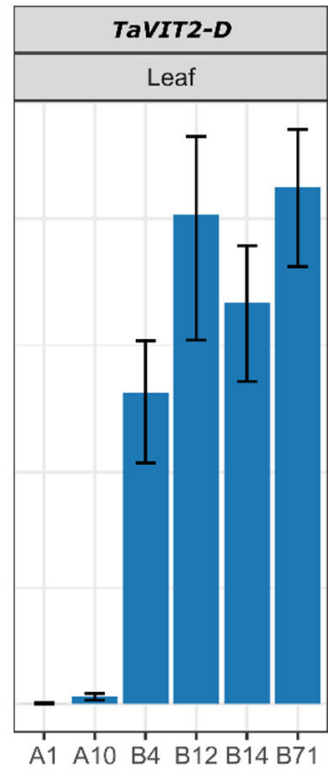
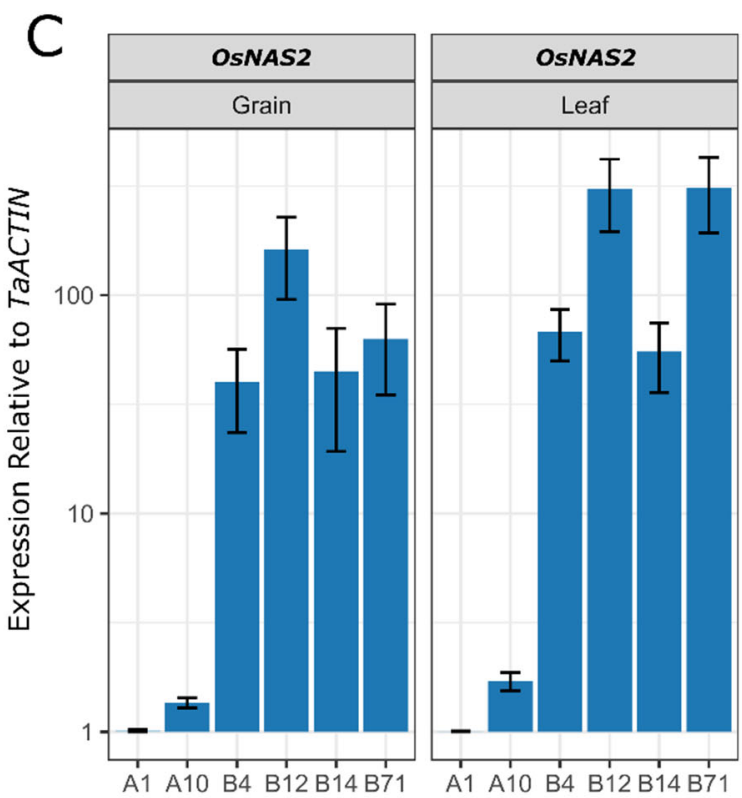

Figure 1: Expression of TaVIT2-D and OsNAS2 in the VIT-NAS lines. A, Diagram of the transfer DNA construct (not to scale): RB, right border; HMWG, HIGH-MOLECULAR-WEIGHT GLUTENIN-D1-1 promoter; TaVIT2-D, wheat (Triticum aestivum) VACUOLAR IRON TRANSPORTER2-D gene; nosT, (bacterial) nopaline synthaseterminator; ZmUBI1, maize (Zea mays) UBIQUITIN promoter; OSNAS2, rice (Oryza sativa) NICOTIANAMINE SYNTHASE 2 gene; 35S, Cauliflower Mosaic Virus 35S promoter; HYG, hygromycin resistance gene; 35ST, Cauliflower Mosaic Virus 35 S terminator; LB, left border. B-C, RT-qPCR expression of (B) TaVIT2-D using primers specific for the transgene and (C) OsNAS2 in grain (left) and flag leaf (right) tissue at 21 days post-anthesis. Expression levels calculated relative to TaACTIN for null transformant (A1) and transgenic (A10, B4, B12, B14, B71) lines. Error bars represent the standard error of three biological replicates for each line.

\section{Combined overexpression of TaVIT2 and OsNAS2 does not affect plant growth.}

To investigate whether expression of the VIT-NAS construct affects plant growth, we measured multiple plant growth and yield parameters for both the cv. Fielder (Fig. 2, Supp. Fig. 1) and cv. Gladius transformants (Supp. Fig. 2). In general, no significant differences were seen between the null transformant A1 and the VIT-NAS lines (Fig. 2B, Supp. Fig. 1 and 2). Some individual lines had a small but significant difference in plant height, with cv. Fielder line $A 10$ shorter than the null segregant, while line B12 was significantly taller ( $p<0.05$, Dunnett Test against A1; Fig. 2). A single transformant from cv. Gladius, BD1-T, had lower tiller number than the corresponding null sibling line $(p<0.001$; Supp. Fig. 2). The average grain area and length was significantly increased in B14 ( $p<0.01$ and 0.001 , respectively; Dunnett Test against A1; Supp. Fig. 1). The remaining lines and traits, including harvest index, grain yield per plant, and thousand grain weight, showed no significant difference against the controls (Fig. 2B, Supp. Fig. 1 and 2). 
bioRxiv preprint doi: https://doi.org/10.1101/2022.02.15.480518; this version posted February 18, 2022. The copyright holder for this

preprint (which was not certified by peer review) is the author/funder, who has granted bioRxiv a license to display the preprint in perpetuity. It is made available under aCC-BY-NC-ND 4.0 International license.

Harrington et al. Iron and zinc biofortification of wheat.

A
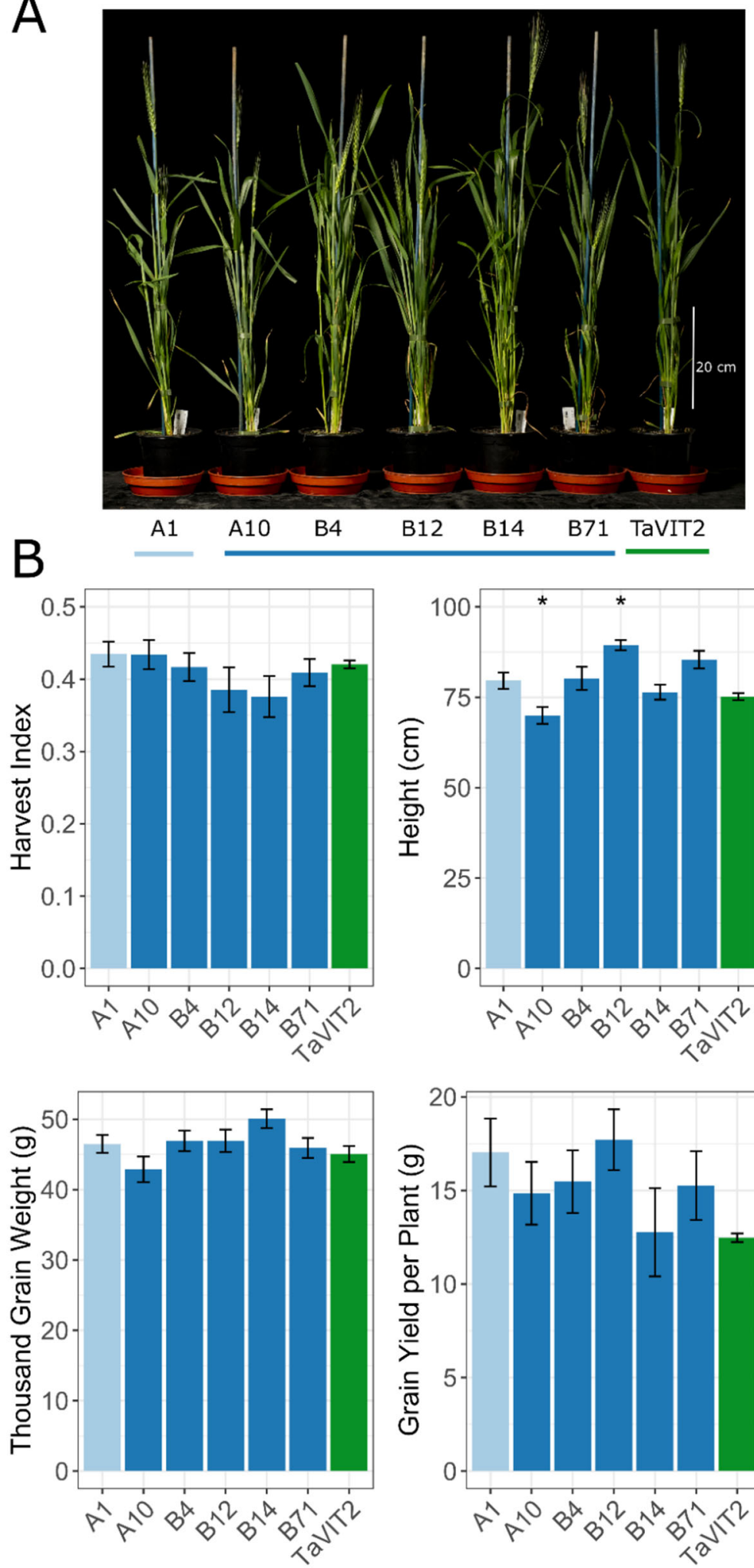

Figure 2: The VIT-NAS construct does not affect plant growth. A, Representative individual wheat plants of the VIT-NAS $\mathrm{T}_{3}$ generation at five days after anthesis. B, Plant growth parameters including harvest index, height, thousand grain weight, and grain yield per plant in the null transformant ( $A 1$; light blue), VIT-NAS (A10, B4, B12, B14, B71; dark blue), and TaVIT2 (green) lines (* $p<0.05$, Dunnett Test against $A 1)$. Error bars are the standard error of five biological replicates. 
Harrington et al. Iron and zinc biofortification of wheat.

\section{The VIT-NAS lines have increased concentrations of iron and zinc in white and wholemeal flours.}

To quantify the levels of iron and zinc in the VIT-NAS grains, grains were hand-milled to obtain wholemeal flour, which was sieved to obtain a crude white flour fraction. Concentrations of key micronutrients were measured using Inductively Coupled Plasma-Optical Emission Spectroscopy (ICPOES). All VIT-NAS lines, in both cV. Fielder and cV. Gladius had approximately 2 -fold higher concentrations of iron in the white flour compared with the controls, which was statistically significant in all Gladius lines and in three of the five Fielder lines ( $p<0.05$, Student's t-test; Fig. 3A and Supp. Fig. 3). The two-fold increase in iron in white flour is similar to that seen in lines transformed with HMWG::TaVIT2 only (Fig. 3A and Ref. 23). In contrast to the TaVIT2 line, all cv. Fielder VIT-NAS lines had significantly higher concentrations of zinc in the white flour fraction compared to the control lines ( $p<0.05$, Student's t-test; Fig. 3A). Similarly, two of the three cv. Gladius VIT-NAS lines had significantly higher white flour zinc concentrations ( $p<0.05$, Student's t-test; Supp. Fig. S3). Therefore, the increase in zinc can be attributed to overexpression of the OsNAS2 gene in the whole plant.

In wholemeal flour, only one VIT-NAS line, B71, had significantly more iron than the control $(p<0.05$, Student's t-test; Fig. 3B). Wholemeal zinc concentrations were increased approximately two-fold in all VIT-NAS lines except A10 ( $p<0.05$, Student's t-test; Fig. 3B). As noted before, the expression level of OsNAS2 in the A10 line is low (Fig. 1B) and thus the A10 line is equivalent to the TaVIT2 line. Correspondingly, wholemeal zinc levels in both $\mathrm{A} 10$ and TaVIT2 are not significantly higher than in the control line. This further demonstrates the specific effect of OsNAS2 overexpression on increasing the grain zinc concentration.

To obtain cleaner white flour fractions, grains from several plants of the VIT-NAS line B71 and a null transformant were milled using a laboratory-scale roller mill. Iron and zinc concentrations are normally between $5-10 \mathrm{\mu g} \mathrm{g}^{-1}$ in Break (B) and Reduction (R) white-flour fractions in industrially milled grain (6), similar to the concentrations we measured in the corresponding white-flour fractions of the null transformant (Fig. 3C). In the VIT-NAS lines, the iron concentration was significantly increased by three to seven-fold, to $23-35 \mu \mathrm{g} \mathrm{g}^{-1}$, and was also significantly increased in the two Fine Bran (FB) fractions ( $p<0.05$, Student's t-test; Fig. $3 C$ ). A less dramatic but significant increase in the zinc concentration was found in the white-flour fractions as well as a two-fold increase in zinc in FB2 and coarse bran (CB). The increased zinc levels in VIT-NAS flour contrast with previous analysis of the TaVIT2 line, which did not have significantly increased zinc in the roller-milled white-flour fractions (12). This emphasizes both the substrate specificity of the iron TaVIT2 transporter (23) and the key role of OsNAS2 expression in increasing zinc in wheat flours. 


\section{A White Flour}
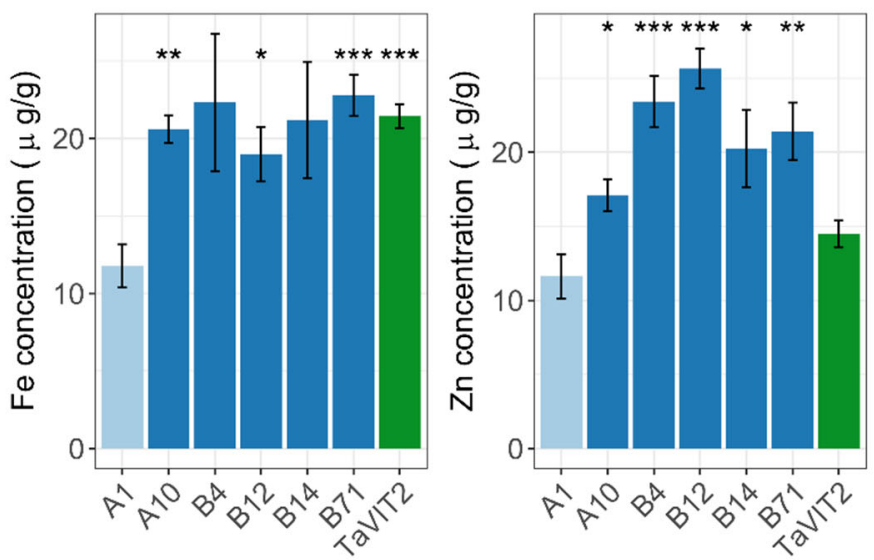

B Wholemeal Flour
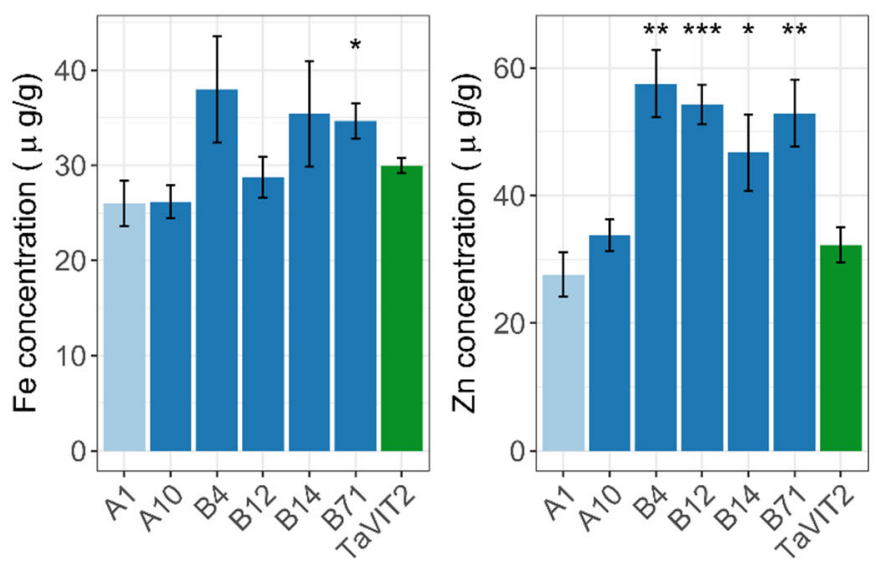

C Roller-Milled Flour Fractions
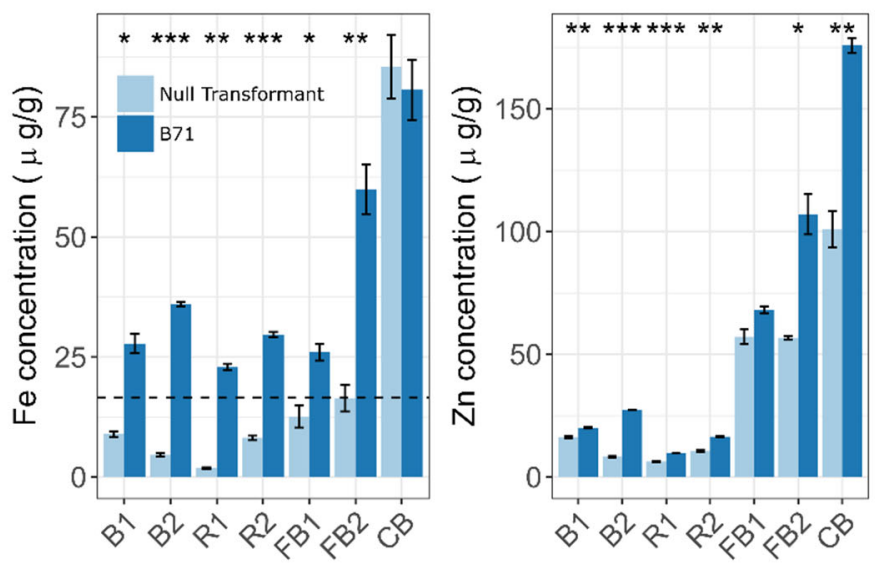

Figure 3: The VIT-NAS lines have increased iron and zinc concentrations. $A$ and $B$, Iron and zinc concentrations measured by ICPOES in white flour (A) and wholemeal flour (B) of the null transformant (A1, light blue), VIT-NAS (A10, B4, B12, B14, B71; dark blue), and TaVIT2 (green) lines in the homozygous $\mathrm{T}_{3}$ generation. Error bars represent the standard error of five biological replicates. Student's t-test against the null (A1); ${ }^{*}, \mathrm{p}<$ $0.05,{ }^{* *}, p<0.01, * * *, p<0.001$. C, Iron and zinc concentrations in roller-milled fractions of grain from a null transformant (light blue) and VIT-NAS (B71, dark blue). B1, first break; B2, second break; R1, first reduction; $R 2$, second reduction; $F B 1$, first fine bran; $F B 2$, second fine bran; $C B$, coarse bran. Dashed line represents the minimum requirement for iron fortification in white flour in the UK $\left(16.5 \mu \mathrm{g} \mathrm{g}^{-1}\right)$. Error bars represent the standard error of three technical replicates. Student's t-test between null and $B 71$ for each fraction; *, $p$ $<0.05,{ }^{* *}, \mathrm{p}<0.01,{ }^{* * *} \mathrm{p}<0.001$. transgenes.

Analysis of hand-milled and roller-milled flour indicated that the VIT-NAS grains accumulate more iron in the tissue which comprises the white flour (endosperm). To further investigate the spatial distribution of iron within the grain, we carried out Perls' staining on cross sections of mature grains. Similar to the TaVIT2 line (34), grains from VIT-NAS lines accumulated iron in the central region of the endosperm, between the maternal vascular bundle and the embryo (Fig. 4A, B). Iron accumulation in the endosperm of TaVIT2 lines is correlated with a decrease in the iron concentration in the aleurone (34), which can be seen by Perls' staining in whole grain cross sections as a lack of a blue outline 
bioRxiv preprint doi: https://doi.org/10.1101/2022.02.15.480518; this version posted February 18, 2022. The copyright holder for this preprint (which was not certified by peer review) is the author/funder, who has granted bioRxiv a license to display the preprint in perpetuity. It is made available under aCC-BY-NC-ND 4.0 International license.

Harrington et al. Iron and zinc biofortification of wheat.

(compare A1 and TaVIT2 in Fig. 4A). By contrast, in the VIT-NAS grains from line B4, B12, B14 and B71, iron is retained in the aleurone tissue, although variation of staining intensity suggests the iron concentration may be less than in control grains.

We also carried out Perls' staining enhanced with diaminobenzidine on thin sections of immature grains from line B71, alongside the TaVIT2 line and the null control. Iron accumulation in globoid clusters was visible in central starchy endosperm cells in both the VIT-NAS and TaVIT2 lines, but not in the control line. Moreover, iron was visibly retained in the aleurone tissue in the B71 line, compared to a strong depletion in the TaVIT2 line (Fig. 4B).

A

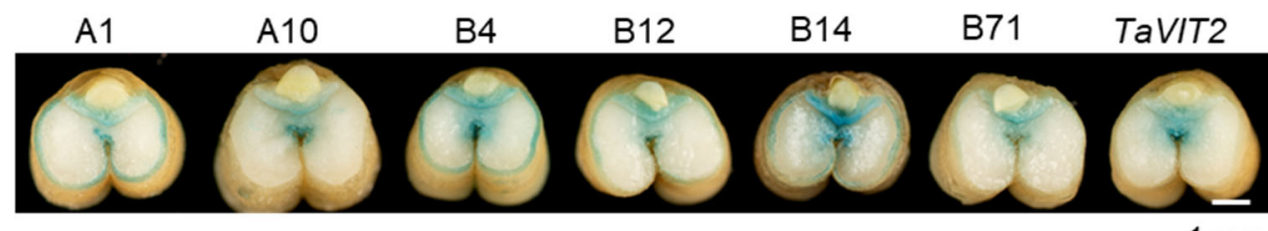

B

Control

(A1)
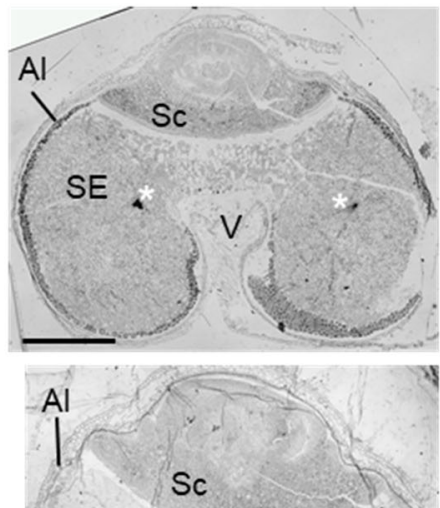

TaVIT2

VIT-NAS

(B71)
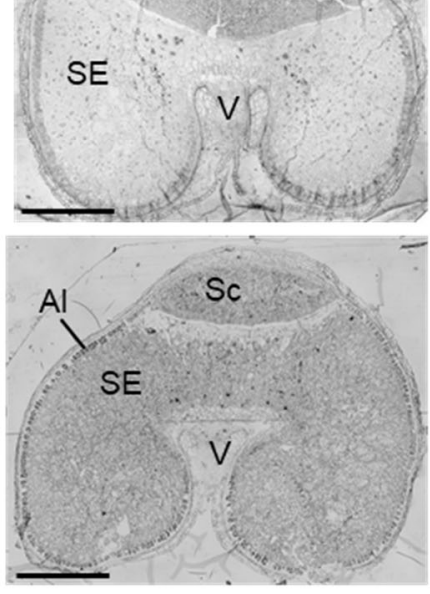

$0.5 \mathrm{~mm}$
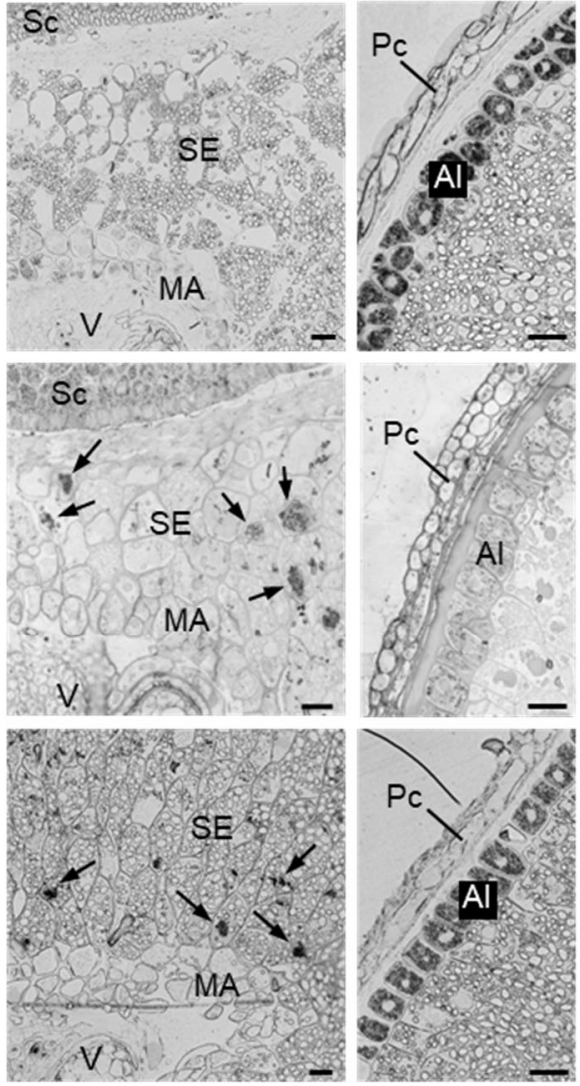

$50 \mu \mathrm{m}$
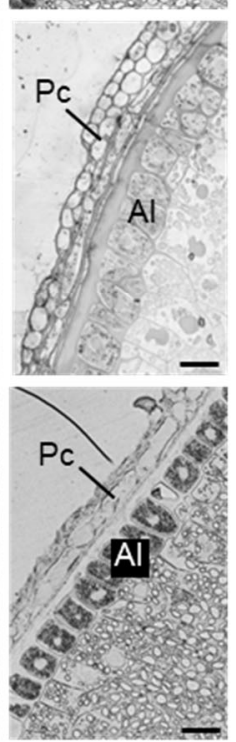

$50 \mu \mathrm{m}$

Figure 4: TaVIT2 and OsNAS2 affect the distribution of iron in the grain. A, Cross sections of mature grains

stained for iron (blue) using the Perls' method. B, Thin sections $(1 \mu \mathrm{m})$ of immature grains 21 days after anthesis stained for iron (black in monochrome images) using the Perls'-diaminobenzidine method. Left, cross section through the grain; middle, detail at higher magnification of the starchy endosperm between the vascular bundle and embryo; right, detail including the aleurone tissue. The images are representative of two grains taken from two different plants from the indicated wheat lines. The TaVIT2 line was previously described (34). Al, aleurone; MA, modified aleurone; Pc, pericarp; Sc, scutellum of the embryo; SE, starchy endosperm; V, vascular bundle (maternal tissue). White asterisk indicates a non-specific dye precipitate; black arrows point at iron accumulation in the vacuoles of starchy endosperm cells. Scale bars as indicated. 
bioRxiv preprint doi: https://doi.org/10.1101/2022.02.15.480518; this version posted February $18,2022$. The copyright holder for this preprint (which was not certified by peer review) is the author/funder, who has granted bioRxiv a license to display the preprint in perpetuity. It is made available under aCC-BY-NC-ND 4.0 International license.

Harrington et al. Iron and zinc biofortification of wheat.

300

\section{The VIT-NAS lines have increased iron and zinc bioaccessibility.}

To measure the extent to which overexpression of OsNAS2 increases the concentration of nicotianamine, we carried out HPLC-MS on wholemeal flour samples (36). We saw significant increases in nicotianamine between three and ten-fold above the control ( $p<0.01$, Mann-Whitney test; Fig. 5A). The wheat line without significantly increased nicotianamine levels, $A 10$, was also the line which had failed to induce OsNAS2 expression (Fig. 1B). The fold increase in NA is similar to that found in grain of lines overexpressing OsNAS2 alone, which were single copy insertion lines (32, 35). Lines with two or more T-DNA inserts, and thus more copies of OsNAS2, displayed only a weak trend for higher grain NA concentrations. The concentration of deoxymugineic acid (DMA), a downstream metabolite of NA also associated with mineral bioavailability, was not measured, however DMA is expected to be approximately $70 \%$ of the NA levels, as shown in extensive analysis in the OsNAS2 wheat lines (32).

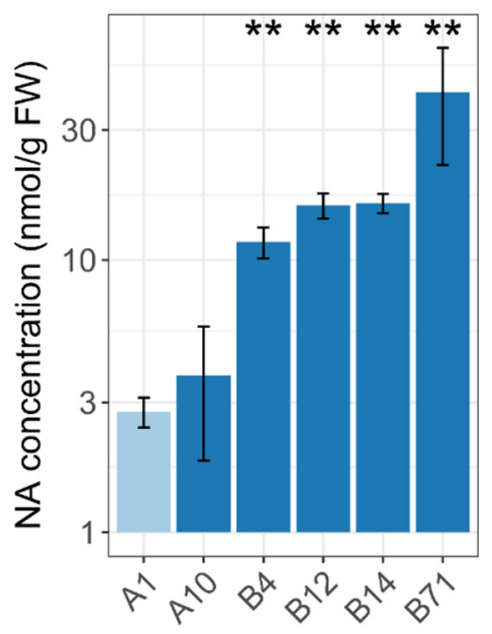

Figure 5: The VIT-NAS lines contain higher levels of nicotianamine. Nicotianamine concentration in grain of the control (A1, light blue) and VIT-NAS (A10, B4, B12, B14, B71, dark blue) lines. Error bars represent the standard error of three biological replicates. ${ }^{* *}, \mathrm{p}<0.01$; MannWhitney test compared to the control line.

We also measured the amount of phytate, an anti-nutrient which inhibits iron and zinc bioavailability, in white and wholemeal flour. We observed no significant differences in phytate concentrations in the VIT-NAS lines compared to the control. This resulted in a two-fold increase in the iron-to-phytate molar ratio in white flour for three of the five lines tested, similar to the TaVIT2 line (Supp. Fig. 4; $p<$ 0.05 , Student's t-test).

We then investigated the bioaccessibility of the iron and zinc levels in white flour from the VIT-NAS lines. Bioaccessibility is the quantity of soluble mineral released during simulated in vitro or in vivo digestion, relative to the total mineral in the food (37). By application of INFOGEST - a consensus, widely-accepted simulated digestion protocol (38) - we found that white flour fractions of the VITNAS line B71 released significantly more iron and zinc during the gastric and duodenal digestion phases relative to control flour from a null transformant line (Table 1A). In the duodenal digestion phase, iron and zinc from control white flour was largely precipitated, but more than double the amount of each mineral remains soluble in the digestate of VIT-NAS white flour (Table 1A). A similar improvement of mineral bioaccessibility was observed using a simulated gastro-intestinal digestion procedure developed for iron uptake studies in Caco-2 cells (39). Roller-milled white flour from the B71 line released 3-fold more iron and 1.3-fold more zinc compared to flour from a null transformant (Table 1B). Taken together, we see that the dramatically increased levels of nicotianamine in the VITNAS lines correlate with enhanced iron and zinc bioaccessibility. 
bioRxiv preprint doi: https://doi.org/10.1101/2022.02.15.480518; this version posted February 18, 2022. The copyright holder for this preprint (which was not certified by peer review) is the author/funder, who has granted bioRxiv a license to display the preprint in perpetuity. It is made available under aCC-BY-NC-ND 4.0 International license.

Harrington et al. Iron and zinc biofortification of wheat.

Table 1: Iron and zinc concentrations in gastro-intestinal digests.

A. Amount of mineral in the soluble (supernatant) and insoluble (pellet) fractions at the end point of simulated digests using the INFOGEST method (38). Values are the average of 3 replicates \pm SD.

\begin{tabular}{lllllllll} 
& & & \multicolumn{2}{c}{ Gastric digest end phase } & \multicolumn{2}{l}{ Duodenum digest end phase } \\
\cline { 3 - 8 } & Sample & $\begin{array}{l}\text { Total } \\
(\mu \mathrm{g})\end{array}$ & $\begin{array}{l}\text { Soluble, } \\
\text { reagent- } \\
\text { derived }\end{array}$ & Supernatant & Pellet & $\begin{array}{l}\text { Soluble, } \\
\text { reagent- } \\
\text { derived }\end{array}$ & Supernatant & Pellet \\
\hline Fe & Control (A1) & 1.64 & 0.03 & $0.43 \pm 0.02$ & $1.26 \pm 0.09$ & 0.63 & $0.57 \pm 0.11$ & $2.23 \pm 0.02$ \\
& NAS-VIT (B71) & 3.01 & & $0.52 \pm 0.03$ & $2.49 \pm 0.20$ & & $1.09 \pm 0.10$ & $3.20 \pm 0.01$ \\
\hline $\mathrm{Zn}$ & Control (A1) & 2.19 & 0.10 & $2.07 \pm 0.10$ & $0.28 \pm 0.08$ & 3.06 & $1.63 \pm 0.14$ & $4.14 \pm 0.13$ \\
& NAS-VIT (B71) & 4.13 & & $3.78 \pm 0.08$ & $0.47 \pm 0.56$ & & $4.45 \pm 0.25$ & $3.54 \pm 0.09$ \\
\hline
\end{tabular}

B. Concentration of mineral released during simulated gastro-intestinal digestion following the method in (39). Values are the average of 3 replicates \pm SD.

\begin{tabular}{llll}
\cline { 3 - 4 } & & Total $(\mu \mathrm{M})$ & Released $(\mu \mathrm{M})$ \\
\hline Fe & Control (22-15) & 6.30 & $6.22 \pm 0.70$ \\
& NAS-VIT (B71) & 31.53 & $20.50 \pm 0.87$ \\
\hline Zn & Control (22-15) & 10.80 & $5.01 \pm 0.47$ \\
& NAS-VIT (B71) & 15.96 & $8.03 \pm 0.25$ \\
\hline
\end{tabular}

\section{DISCUSSION}

Efforts to biofortify wheat must address two concerns- not only the levels of micronutrients, but also their bioavailability in human digestion. Here we show that by combining constitutive expression of the rice OsNAS2 gene with endosperm-specific expression of the wheat VIT2-D gene, we can significantly increase both the quantity of iron and zinc in wheat flours and the solubility of these two mineral micronutrients in simulated gastro-intestinal digests of raw white flour. Greater solubility is likely to enhance the bioavailability of iron and zinc, although this remains to be tested in cell culture and human studies using baking products such as white and wholemeal bread.

Expression analysis of the transgenes by RT-qPCR confirmed high levels of OsNAS2 in both leaf tissue and grain (Fig. 1C), but unexpectedly showed that the TaVIT2-D transgene was expressed in leaf tissue in all but one of the VIT-NAS lines (Fig. 1B). The HMWG promoter upstream of TaVIT2-D is well characterized as an endosperm-specific promoter (40), and indeed the A10 line, with a single-copy insertion of the T-DNA, showed the desired expression pattern. We hypothesise that in multi-copy insertion lines the 35S promoter of the HYG resistance marker acts as an enhancer for TaVIT2-D expression as noted previously in Arabidopsis studies ((41) and references therein). Leaves normally have 3.5x higher expression of the TaVIT2 homeologs compared to grain (33), and from our phenotypic analysis there are no detrimental effects on plant growth parameters (Fig. 2, Supp. Fig. 1).

The results show that the desired effects of each expression cassette, HMWG::TaVIT2 and ZmUBI1::OsNAS2, are additive. In some of the high-purity white flour fractions, we see more than fivefold improvement in the iron concentration, while the zinc concentration increased two-to-three fold (Fig. 3C). Earlier research which combined introduction of gene cassettes for endosperm-specific expression of ferritin and UBI1::OsNAS2, a strategy that was successful in rice, did not show additive 
effects on the mineral micronutrient content of flour and whole grain in wheat, but increases that were similar to ferritin alone (30). Possibly, entrapment of iron in the groove as a result of overexpressed ferritin (31) could have inhibitory effects on translocation of zinc into the grain mediated by NA. Another possibility is that ferritin protein in starchy endosperm cells captures only a small amount of the iron that is in transit to the embryo and aleurone cells, because the iron would need to be transported first into the plastids, across a double membrane, prior to storage in the ferritin cavity. By contrast, TaVIT2 directly transports iron from the cytosol into vacuoles for storage.

The altered distribution of iron in grain tissues of the VIT-NAS lines, caused by the unique combination of TaVIT2 and OSNAS2 expression, gives additional insights into the process of iron translocation during grain development, which is still poorly understood. Like the TaVIT2 line, the VIT-NAS lines accumulated iron in vacuolar globules within cells of the starchy endosperm that are located between the vascular bundle and embryo (Fig. 4B). However, unlike the TaVIT2 line, the VIT-NAS line also retained iron within the aleurone layer, similar to that observed in the null control (Fig. 4B). Isotope labelling studies combined with NanoSIMS showed that iron is trapped into the endosperm vacuoles during the nutrient-filling stage of grain development in TaVIT2 lines (34). We speculate that the retention of iron within the endosperm prevents iron from completing its movement to the outer aleurone layer. In contrast, the overexpression of OsNAS2 in the VIT-NAS lines seems to maintain the mobilisation of iron into the aleurone layer despite the overexpression of TaVIT2 (Fig. 4B). Perhaps the distinct expression profiles of the constitutive $Z m U B I 1$ and the endosperm-specific HMWG promoters for OSNAS2 and TaVIT2-D, respectively, drive this difference. The HMWG promoter sequence used here is strongly activated around 14 days post-anthesis as shown by promoter:GUS studies (40). We hypothesize that expression of OsNAS2 in the early stages of grain development promotes movement of iron (and other micronutrients such as zinc) into the grain, during which time they are transported to the outer grain layers including the aleurone cells and the embryo. Later, once the HMWG promoter is induced, expression of TaVIT2 within the endosperm tissue leads to the sequestration of iron in the vacuoles of endosperm cells, as in the TaVIT2 transgenic line. The VIT-NAS line $A 10$ supports this hypothesis, as we see iron accumulation only in the endosperm of the grain (Fig. 4A). As this line failed to overexpress the OsNAS2 gene (Fig. 1B), it emphasizes the importance of that gene in driving the accumulation of iron in the outer layers of the grain.

Crucially, the absolute levels of zinc of at least $45 \mu \mathrm{g} \mathrm{g}{ }^{-1}$ in the VIT-NAS lines are above the biofortification target of $38 \mu \mathrm{g} \mathrm{g}^{-1}$ (dry weight) set for whole wheat flour by HarvestPlus (42). The target for iron is $59 \mathrm{\mu g} \mathrm{g}^{-1}$, but this number assumes only $5 \%$ bioavailability in wholemeal flour. Depending on the cultural preference for consuming white or wholemeal flour, and the expected improvement in iron bioavailability, the iron concentrations of $25 \mu \mathrm{g} \mathrm{g}^{-1}$ and $30 \mu \mathrm{g} \mathrm{g}^{-1}$ in white and wholemeal flour, respectively, may be sufficient to achieve $30 \%$ of the estimated average requirement (EAR) of iron in the diet.

INFOGEST is fast emerging as the model digestion protocol to assess the bioaccessibility of multiple micronutrients including iron. The Glahn protocol (39) is currently used as a standard in the iron nutrition community for assessing iron release and subsequent absorption by ferritin production in Caco- 2 cell culture, which has a strong positive correlation with results from human trials (37). While the Glahn protocol is facile, INFOGEST provides a robust framework for controlling many parameters including enzyme activity. In this study, improved iron release associated with the VIT-NAS flour was reflected in both digestion protocols. Phytate concentration was not significantly different between control and VIT-NAS flours (Supp. Fig. 4). For this reason, we argue that the enhanced mineral bioaccessibility seen in VIT-NAS white flour digests is a consequence of iron or zinc bound to 
nicotianamine which may exert preferential cation chelation compared with phytic acid. This hypothesis will be investigated by HPLC-ICP-MS in the near future.

The ultimate aim is for biofortified wheat to be grown by farmers in different parts of the world and for it to be incorporated into human diets. We found no evidence of detrimental growth effects caused by the introduction of the VIT-NAS construct (Fig. 2, Supp. Fig. 1 and 2). This will need to be further studied in field trials, but the initial data suggests that the VIT-NAS construct does not affect key agronomic traits and may thus be acceptable to farmers. It will also be important to confirm that the increased nutrient levels and bioaccessibility identified in these glasshouse trials can be replicated in the field. Promisingly, field-trials previously carried out with OsNAS2 wheat constitutive expression lines showed increased nutrient levels and bioavailability across multiple field sites and years (32). Importantly, we show the effect of the VIT-NAS construct in two distinct wheat cultivars, Fielder and Gladius. In particular, cv. Gladius is widely grown by farmers in Australia and is known for its useful agronomic traits such as drought tolerance. The success of the VIT-NAS construct in cv. Gladius, improving micronutrient levels with no observed impact on measured plant growth traits, indicates that it could be effectively incorporated into other elite wheat varieties. A further consideration when taking a genetic-modification approach for biofortification is the regulatory landscape governing the use of such lines. It may be beneficial to develop a version of the VIT-NAS construct which uses only wheat-derived genetic sequence within the T-DNA. Research into the most appropriate wheat NAS gene would be required, as would replacement of the bacterial reporter genes with alternatives.

In conclusion, the stacking of HMWG::TaVITD-2 and UBI1::OsNAS2 results in much higher grain iron and zinc concentrations in cultivated wheat varieties than those observed in natural variety panels of wheat. Moreover, the increased NA levels are likely to compete with phytic acid to improve bioavailability of the mineral micronutrients. Future field trials are needed to confirm the results and to bulk up material for making wheat products for nutritional studies.

\section{MATERIALS AND METHODS}

\section{Vector construction and wheat transformation}

The VIT-NAS construct was generated by inserting the HMWG::TaVIT2-D cassette (33) between the TDNA right border (RB) and ZmUBI1::OsNAS2 cassette (35) in a modified pMDC32 vector backbone (43), see Fig. 1A. The HMWG::TaVIT2-D sequence was inserted by In-Fusion cloning (Takara Bio) in the HindIII restriction site upstream of ZmUBI1::OsNAS2, using primers JC172 and JC173 (Suppl. Table 1). Thus, the TaVIT2-D gene (TraesCS5B02G202100) is under the control of the High Molecular Weight Glutenin-D1 (HMWG) promoter (40), resulting in ectopic expression of TaVIT2-D in the grain endosperm (33). The OsNAS2 gene (Os03g0307200) is under transcriptional control of the maize ubiquitin promoter $Z m U B I 1$ for constitutive expression (44). The T-DNA also contains the plant-specific hygromycin resistance marker (43). The TaVIT2 and OSNAS2 genes were terminated by the nopaline synthase terminator (nosT), while the hygromycin resistance gene was terminated by the CaMV 3' untranslated region. See Supp. Fig. 5 for a detailed map of the vector construct.

The transformation of wheat cultivar Fielder was carried out at the John Innes Centre, following the protocol detailed in (26). A zero-copy null transformant, referred to here as A1, was used as a control. At each generation, copy number analysis was carried out by iDNA Genetics (Norwich, UK) using a Taqman probe against the hygromycin resistance gene (45). Grain from the homozygous $T_{3}$ generation was used for the micronutrient content and nicotianamine analyses reported here. The TaVIT2 line used as a control has been described in $(33,34)$. 
The transformation of wheat cultivar Gladius was carried out at the University of Adelaide following the protocol details in (46). Copy number analysis was carried out on the $T_{0}$ plants by quantitative realtime PCR (qPCR) using primers specific to the VIT-NAS construct (Supplemental Table 1). Individual $T_{0}$ plants which contained single copy inserts (denoted with a "-T" ending) were selected for further characterisation in the $T_{2}$ generation, alongside sibling null segregant lines (denoted with the "- $N$ " ending).

\section{Plant growth}

For all cv. Fielder experiments, seeds were pre-germinated for 48 hours at $4{ }^{\circ} \mathrm{C}$ on moist filter paper. They were then sown into P96 trays containing peat-based soil ( $85 \%$ fine peat, 15\% horticultural grit). At 21 days, the plants were transplanted into 1-liter individual pots containing Petersfield Cereal Mix (Petersfield, Leicester, UK). The plants were arranged in a randomised block design and grown in standard glasshouse conditions with 16:8 hour light:dark cycles.

For all cv. Gladius experiments, seeds were pre-germinated for 48 hours at $4{ }^{\circ} \mathrm{C}$, after which they were germinated in $\mathrm{P} 56$ plug trays containing soil supplemented by $4.5 \mathrm{~g} \mathrm{l}^{-1}$ Osmocote (Scotts Australia). After two weeks, plants were transplanted into 1-liter pots containing the same soil. The plants were grown in a randomised block design, initially at a constant temperature of $24^{\circ} \mathrm{C}$ during the day, and $18^{\circ} \mathrm{C}$ at night. After transplanting to individual pots, the plants were moved to an accelerated "speed breeding" growth condition (47).

\section{Plant phenotyping}

Plant phenotyping data from the cv. Fielder plants was obtained at harvest. Plant height was measured from the soil to the tip of the highest spike, excluding awns. The entire above-ground plant was harvested and dried at $35^{\circ} \mathrm{C}$ for one week to obtain the total above-ground dry weight. Harvest index was calculated as the ratio of the total plant grain yield (g) to the total above-ground dry weight (g). After threshing, grain yield per plant was calculated and the thousand grain weight and grain area, width, and length were obtained using the MARVIN seed analyser (GTA Sensorik GmbH). Plant phenotyping data from the cv. Gladius plants was obtained in the same manner, with the exception that plant material was dried at $45^{\circ} \mathrm{C}$ for $72 \mathrm{~h}$ to obtain the total above-ground dry weight.

\section{RT-qPCR}

Leaf and grain tissues were sampled from individual $T_{3}$ VIT-NAS plants (cv. Fielder) at 21 days postanthesis and snap frozen in liquid $N_{2}$. The snap-frozen tissue was then ground in liquid $\mathrm{N}_{2}$ to a fine powder and RNAs were extracted using TRIzol ${ }^{\circledR}$ Reagent (ThermoFisher). RNA concentration and purity was checked using a Nanodrop instrument (Thermo Scientific). DNase treatment was carried out using RQ1 RNase-Free DNase (Promega) before cDNAs were synthesized using the Invitrogen MMLV reverse transcriptase.

Primers specific to the gene sequences introduced within the VIT-NAS construct were used, while previously published primers were used for the internal control TaACTIN (Supp. Table 2) (19). Primer efficiencies were calculated using pooled grain cDNA from lines B4, B14, B12, and B71 (Supp. Table 3). RT-qPCR reactions were performed using the LightCycler ${ }^{\circledR} 480$ SYBR Green I Master Mix with a LightCycler 480 instrument (Roche Applied Science, UK) under the following conditions: 5 min at $95^{\circ} \mathrm{C}$; 45 cycles of $10 \mathrm{~s}$ at $95^{\circ} \mathrm{C}, 15 \mathrm{~s}$ at $60^{\circ} \mathrm{C}, 30 \mathrm{~s}$ at $72^{\circ} \mathrm{C}$; followed by a dissociation curve from $60^{\circ} \mathrm{C}$ to $95^{\circ} \mathrm{C}$ to determine primer specificity. In all cases, three technical replicates were carried out per sample and the construct-specific expression of TaVIT2-D and OsNAS2 was recorded relative to TaACTIN. 


\section{Flour production}

For cv. Fielder, grains were hydrated to approximately $12 \%$ moisture content and milled with an IKA Tube Mill 100 for 2 minutes at 25000 RPM. The resulting wholemeal flour was passed through a 150 $\mu \mathrm{m}$ Nylon mesh to separate a crude white flour fraction from the bran. The wholemeal flour and the white flour fraction were retained for downstream analysis.

For cv. Gladius, grains were washed in a $0.1 \%$ Tween 20 solution, rinsed in distilled water, and dried at $60^{\circ} \mathrm{C}$ for 48 hours before milling using an IKA Tube Mill for 30 seconds at 20000 RPM. The wholemeal flour was then passed through a $200 \mu \mathrm{m}$ Nylon mesh to obtain the white flour fraction.

For roller milled flour fractions, grain was hydrated to approximately $15 \%$ moisture content and milled using a Chopin CD1 laboratory mill. The pooled white flour for bioaccessibility assays consisted of 9.5 $\mathrm{g}$ of Break 1, $11.5 \mathrm{~g}$ of Reduction 1, $1.5 \mathrm{~g}$ of Break 2 and $2 \mathrm{~g}$ of Reduction 2 for the control flour of the 22-15 null transformant line; $9.8 \mathrm{~g}$ of Break 1, $11.5 \mathrm{~g}$ of Reduction 1, $1.5 \mathrm{~g}$ of Break 2 and $2 \mathrm{~g}$ of Reduction 2 for the B71 line.

\section{Elemental analysis}

For cv. Fielder samples, flour was dried overnight at $65^{\circ} \mathrm{C}$. Flour samples $(0.1 \mathrm{~g})$ were digested in $55 \%$ $(\mathrm{v} / \mathrm{v})$ nitric acid and $6 \%(\mathrm{v} / \mathrm{v})$ hydrogen peroxide at $95^{\circ} \mathrm{C}$ for 17 hours. The acid-digested samples were $5 \times$ diluted with ultra-pure analytical grade water. The samples were analysed using inductively coupled plasma-optical emission spectroscopy (ICP-OES, PlasmaQuant PQ 9000 Elite, Jena Analytik, Germany). Calibration was performed using $0,0.125,0.25,0.5,1,2,3,4$ and $5 \mu g^{-1}$ standards of $P$ and $\mathrm{Mg}$ and $0,0.025,0.05,0.1,0.2,0.4,0.6,0.8$ and $1 \mu \mathrm{g} \mathrm{g}^{-1}$ standards of $\mathrm{Mn}$, Fe and $\mathrm{Zn}$. Rhodium (Rh), to a final concentration of $0.1 \mu \mathrm{g} \mathrm{g}^{-1}$, was used as an internal standard. Hard red spring wheat reference material (National Research Council Canada) was treated in the same manner as the experimental samples and included in every run of 50 samples.

For cv. Gladius samples, the white flour fraction was analysed using ICP-OES following standard procedures at the Trace Analysis for Chemical, Earth, and Environmental Sciences (TrACEES) platform (Parkville, University of Melbourne). 1567b wheat flour was used as the standard reference material (National Institutes of Standards and Technology, MD, USA).

\section{Nicotianamine quantification}

The concentration of nicotianamine was measured in water-based extracts using liquid chromatography-mass spectrometry (LC-MS), following the method in (36) with minor modifications. Approximately $0.5 \mathrm{~g}$ of wholemeal flour was mixed with $282 \mu \mathrm{l}$ of milliQ water and $18 \mu \mathrm{l}$ of $1 \mathrm{mM} N^{\varepsilon}$ nicotinoyl-L-lysine (see below) which was added as internal standard. The mixture was ground for 5 min at $1000 \mathrm{rpm}$ and centrifuged at $4^{\circ} \mathrm{C}$ at $15000 \times \mathrm{g}$ for $15 \mathrm{~min}$ to recover the supernatant. The pellet was extracted another 4 times with $300 \mu \mathrm{l}$ water and the 5 supernatants pooled, then filtered through $3 \mathrm{kDa}$ filters (Amicon ${ }^{\circledR}$ Ultra) at $4^{\circ} \mathrm{C}$ at $15000 \times g$ for $60 \mathrm{~min}$. The extracts and $1 \mu \mathrm{M}, 10 \mu \mathrm{M}, 100 \mu \mathrm{M}$ and $200 \mu \mathrm{M}$ standard solutions of nicotianamine (US Biological Life Sciences) each containing $83 \mathrm{mM}$ $N^{\varepsilon}$-nicotinoyl-L-lysine were lyophilized overnight. The residues were dissolved in $20 \mu$ of milliQ water, $10 \mu \mathrm{l} 50 \mathrm{mM}$ EDTA and $30 \mu \mathrm{l}$ of mobile phase $\mathrm{A}$ (1:10 ratio of $10 \mathrm{mM}$ ammonium acetate to acetonitrile, $\mathrm{pH} 7.1$ ) before being filtered through $0.45 \mu \mathrm{m}$ polyvinylidene fluoride (PVDF) ultrafree-MC centrifugal filters (Durapore, Merck) for $10 \mathrm{~min}$ at $12000 \times \mathrm{g}$. The samples were then analysed by LC-MS (Xevo TQ-S, Waters). The separation was performed using a Waters Acquity Ultra Performance LC system and a $\mu$ LC column (SeQuant ${ }^{\circledR}$ ZIC $^{\circledR}-$ HILIC, $150 \times 1 \mathrm{~mm}$ internal diameter, $5 \mu \mathrm{m}, 200 \AA$ ) equipped with a guard column. The flow rate of the mobile phases was set to $0.15 \mathrm{ml} \mathrm{min}^{-1}$. The gradient program was set to $100 \%$ mobile phase $A$ for $3 \mathrm{~min}$; a linear gradient to $30 \% \mathrm{~A}$ and $70 \% \mathrm{~B}(8: 2$ ratio of $30 \mathrm{mM}$ ammonium acetate to acetonitrile, $\mathrm{pH} 7.3$ ) over $7 \mathrm{~min} ; 30 \% \mathrm{~A}$ and $70 \% \mathrm{~B}$ for $7 \mathrm{~min}$; a gradient to $100 \%$ 
A for $8 \mathrm{~min} ; 100 \%$ A for $10 \mathrm{~min}$. The total run time for each sample was $35 \mathrm{~min}$, the injection volume was $5 \mu \mathrm{l}$ and the auto sampler temperature was $6^{\circ} \mathrm{C}$, whilst the column was at room temperature. The liquid chromatography system was coupled to a time of flight-mass spectrometer (ToF-MS) with a negative electrospray source. The spray chamber conditions were set to a spray voltage of $1.5 \mathrm{kV}$, a desolvation temperature of $500^{\circ} \mathrm{C}$, flow rates were $900 \mathrm{~h}^{-1}$ and $150 \mathrm{~h}^{-1}$ for the desolvation and cone gas, respectively, and the nebuliser pressure was set to 7.0 bar. The TargetLynx V4.1 (Waters Inc) software was used for quantification. The 302 to $186 \mathrm{~m} / z$ daughter transition was used to quantify nicotianamine and the 250 to $78 \mathrm{~m} / \mathrm{z}$ daughter transition was used to quantify $N^{\varepsilon}$-nicotinoyl-L-lysine.

\section{Bioaccessibility assays}

Simulated digestion following the INFOGEST method was performed as described in (48) with minor modifications. Hand-milled white flour $(0.2 \mathrm{~g})$ was mixed with $600 \mu \mathrm{l}$ of water to obtain a homogenous bolus. For the oral phase, $640 \mu \mathrm{l}$ of simulated salivary fluid was added to the bolus, $1.5 \mathrm{mM} \mathrm{CaCl}_{2}\left(\mathrm{H}_{2} \mathrm{O}\right)_{2}$ and $156 \mu$ l of water. Human salivary amylase was omitted as oral starch digestion was not of interest. The mixture was incubated for $2 \mathrm{~min}$ at $37^{\circ} \mathrm{C}$. For the gastric phase, the $\mathrm{pH}$ was adjusted to $3.0 \mathrm{using}$ $0.5 \mathrm{M} \mathrm{HCl}$, and $1.36 \mathrm{ml}$ of simulated gastric fluid (as defined in $\operatorname{Ref} 46$ ), $0.15 \mathrm{mM} \mathrm{CaCl}_{2}\left(\mathrm{H}_{2} \mathrm{O}\right)_{2}$, and 96 $\mu$ l of water was added. Pepsin (Merck P7012, pepsin from porcine gastric mucosa) was added to a final concentration of $2,000 \mathrm{U} / \mathrm{ml}$. Lipases were omitted owing to the low lipid content of the flours. Samples were incubated for $1 \mathrm{~h}$ at $37^{\circ} \mathrm{C}$. For the duodenal phase, $1.68 \mathrm{ml}$ of simulated intestinal fluid (46) was added to the gastric mixture, adjusting the $\mathrm{pH}$ to 7.0. To this was added $10 \mathrm{mM}$ bovine bile salts (Merck B3883), $0.6 \mathrm{mM} \mathrm{CaCl}\left(\mathrm{H}_{2} \mathrm{O}\right)_{2}, 100 \mathrm{U} / \mathrm{ml}$ porcine trypsin (Merck T4799), $25 \mathrm{U} / \mathrm{ml}$ bovine chymotrypsin (Merck C4129) and $200 \mathrm{U} / \mathrm{ml}$ porcine pancreatic $\alpha$-amylase (A3176), was added. Pancreatic lipase and colipase were omitted. The intestinal phase was incubated at $37^{\circ} \mathrm{C}$ for $2 \mathrm{~h}$.

At the end of each digestion phase, samples were centrifuged at $1000 \times g$ for $5 \mathrm{~min}$. Supernatants were decanted for analysis of soluble minerals; pellets were resuspended in $1 \mathrm{ml}$ of analytical grade water and also analysed to obtain total values of iron and zinc for each sample. Gastric endpoint samples ( $2.5 \mathrm{ml}$ supernatant) were acid mineralised in $16 \% \%(\mathrm{w} / \mathrm{v}) \mathrm{HNO}_{3}$ and $1.7 \%(\mathrm{w} / \mathrm{v}) 0.2 \mathrm{ml} \mathrm{H}_{2} \mathrm{O}_{2}$ at $95^{\circ} \mathrm{C}$ for $16 \mathrm{~h}$, then made up to $4 \mathrm{ml}$ with ultrapure water. Duodenal endpoint samples $(6.4 \mathrm{ml}$ supernatant) were frozen in liquid nitrogen and lyophilized prior to elemental analysis as described for flour.

Simulated gastrointestinal digestion following the Glahn protocol was performed as described in (39). Pooled, roller-milled white flour $(1 \mathrm{~g})$ samples were mixed with $10 \mathrm{ml}$ of saline solution $(140 \mathrm{mM} \mathrm{NaCl}$ and $5 \mathrm{mM} \mathrm{KCl}, \mathrm{pH} 2.0$ ) and adjusted to $\mathrm{pH} 2.0$ with $1 \mathrm{M} \mathrm{HCl}$. To this, $0.5 \mathrm{ml}$ of pepsin (Sigma-P7000; $16 \mathrm{mg} \mathrm{ml}^{-1}$ ) was added. Samples were incubated at $37^{\circ} \mathrm{C}$ on a rocking platform (150 rpm) for $90 \mathrm{~min}$. The $\mathrm{pH}$ of the samples was then adjusted to $\mathrm{pH} 5.5$ using $1 \mathrm{M} \mathrm{NaHCO}_{3}$. Bile extract (Sigma-B8631; 8.5 $\mathrm{mg} \mathrm{ml}^{-1}$ ) and pancreatin (Sigma-P1750; $1.4 \mathrm{mg} \mathrm{l}^{-1}$ ) was added at $2.5 \mathrm{ml}$, and the $\mathrm{pH}$ was adjusted again to $\mathrm{pH}$ 7.0. The solution was made up to $16 \mathrm{ml}$ with saline solution $(140 \mathrm{mM} \mathrm{NaCl}$ and $5 \mathrm{mM} \mathrm{KCl}, \mathrm{pH}$ 7.0), and the samples were incubated at $37^{\circ} \mathrm{C}$ for $90 \mathrm{~min}$. Samples were centrifuged at $1000 \times \mathrm{g}$ for 5 mins to separate the soluble mineral fraction and insoluble food pellet. For mineral quantification, $250 \mu \mathrm{l}$ of supernatant was added to $14.75 \mathrm{ml} \mathrm{HNO}_{3}$ (17.5\%) containing $1 \mathrm{mg} \mathrm{^{-1 }}$ Yttrium (Merck Millipore) as an internal standard. Mineral content in the samples were analysed using ICP-OES (Thermo Fisher iCAP 6300).

\section{Iron staining}

Whole, mature wheat grains were cut with a platinum-coated razor blade and immersed in $2 \%(\mathrm{w} / \mathrm{v})$ potassium ferrocyanide and $2 \%(\mathrm{v} / \mathrm{v}) \mathrm{HCl}$ for $45 \mathrm{~min}$, then washed with water and photographed. Grain 
bioRxiv preprint doi: https://doi.org/10.1101/2022.02.15.480518; this version posted February $18,2022$. The copyright holder for this preprint (which was not certified by peer review) is the author/funder, who has granted bioRxiv a license to display the preprint in perpetuity. It is made available under aCC-BY-NC-ND 4.0 International license.

Harrington et al. Iron and zinc biofortification of wheat.

cross sections $(1 \mu \mathrm{m})$ were prepared as previously described, mounted on glass slides and stained for iron using the Perls' method enhanced with diaminobenzidine (34). In brief, the slides were immersed in $2 \%(\mathrm{w} / \mathrm{v})$ potassium ferrocyanide and $2 \%(\mathrm{v} / \mathrm{v}) \mathrm{HCl}$ for $45 \mathrm{~min}$. After washing with distilled water, samples were incubated in methanol containing $0.01 \mathrm{M} \mathrm{NaN}_{3}$, and $0.3 \%(\mathrm{w} / \mathrm{v}) \mathrm{H}_{2} \mathrm{O}_{2}$ for $60 \mathrm{~min}$. The slides were washed with $0.1 \mathrm{M}$ phosphate buffer $(\mathrm{pH} 7.4)$ and incubated for 30 minutes with $1.8 \%$ $(\mathrm{w} / \mathrm{v}) \mathrm{CoCl}_{2} .6 \mathrm{H}_{2} \mathrm{O}$ and $0.025 \%(\mathrm{w} / \mathrm{v})$ diaminobenzidine in phosphate buffer. The slides were washed once with distilled water and left to air dry overnight and mounted with DPX mountant (Merck). The slides were imaged using a Leica DM6000 at 10x magnification.

\section{Acknowledgements}

We would like to thank Sadiye Hayta, Mark Smedley and Wendy Harwood (John Innes Centre, JIC) for wheat transformation; Julien P. Bonneau for growth of Gladius transformants; JIC Horticulture staff for plant growth; Alison Lovegrove (Rothamsted Research) for roller milling; Marina Franceschetti (JIC) for ICP-OES; Martin Rejzek (JIC Chemistry Platform) for synthesis of nicotinoyl-L-lysine; Ana ÁlvarezFernández (Spanish National Research Council, CSIC) for advice on nicotianamine quantification; Lionel Hill (JIC Metabolomics Platform) for assistance with LC-MS; Kirstie Halsey (Rothamsted Research) for sample preparation for microscopy; Shailender Verma for iron staining of TaVIT2 sections; Eva Wegel (JIC Bio-imaging Platform) for microscopy training and assistance.

\section{Funding}

This work was supported by the Biotechnology and Biological Sciences Research Council, grant awards BB/P019072/1 to J.M.C., M.F.A., P.A.S., C.U. and J.B. and BB/T004363/1 to S.A.H., C.U. and J.B.; funding from HarvestPlus to N.I.M.N and A.A.T.J.; a studentship from the John Innes Foundation to R.M. and a Wellcome Trust studentship to Y.M.L.M.

\section{References}

1. WHO. Worldwide prevalence of anaemia 1993-2005 : WHO global database on anaemia. Geneva: World Health Organisation; 2020.

2. WHO. The global prevalence of anaemia in 2011. Geneva: World Health Organisation; 2015.

3. Ritchie H, Roser M. Micronutrient deficiency: Our World in Data; 2017 [Available from: https://ourworldindata.org/micronutrient-deficiency.

4. Kumssa DB, Joy EJM, Ander EL, Watts MJ, Young SD, Walker S, et al. Dietary calcium and zinc deficiency risks are decreasing but remain prevalent. Sci Rep. 2015;5(1):10974.

5. FAO. FAOSTAT Data 2021 [Available from: http://www.fao.org/faostat/en/\#data.

6. Balk J, Connorton JM, Wan Y, Lovegrove A, Moore KL, Uauy C, et al. Improving wheat as a source of iron and zinc for global nutrition. Nutr Bull. 2019;44(1):53-9.

7. O'Dell BL, De Boland AR, Koirtyohann SR. Distribution of phytate and nutritionally important elements among the morphological components of cereal grains. J Agric Food Chem. 1972;20(3):718-23.

8. Ozturk L, Yazici MA, Yucel C, Torun A, Cekic C, Bagci A, et al. Concentration and localization of zinc during seed development and germination in wheat. Physiol Plant. 2006;128(1):144-52.

9. Cakmak I, Kalayci M, Kaya $Y$, Torun AA, Aydin N, Wang $Y$, et al. Biofortification and localization of zinc in wheat grain. J Agric Food Chem. 2010;58(16):9092-102.

10. Moore KL, Zhao F-J, Gritsch CS, Tosi P, Hawkesford MJ, McGrath SP, et al. Localisation of iron in wheat grain using high resolution secondary ion mass spectrometry. J Cereal Sci. 2012;55(2):183-7.

11. Tang J, Zou C, He Z, Shi R, Ortiz-Monasterio I, Qu Y, et al. Mineral element distributions in milling fractions of Chinese wheats. J Cereal Sci. 2008;48(3):821-8.

12. Hurrell R, Egli I. Iron bioavailability and dietary reference values. Am J Clin Nutr. 2010;91(5):1461s-7s.

13. Gibson RS, Raboy V, King JC. Implications of phytate in plant-based foods for iron and zinc bioavailability, setting dietary requirements, and formulating programs and policies. Nutr Rev. 2018;76(11):793-804.

14. Khokhar JS, King J, King IP, Young SD, Foulkes MJ, De Silva J, et al. Novel sources of variation in grain Zinc (Zn) concentration in bread wheat germplasm derived from Watkins landraces. PLoS One. 2020;15(2):e0229107. 
bioRxiv preprint doi: https://doi.org/10.1101/2022.02.15.480518; this version posted February $18,2022$. The copyright holder for this preprint (which was not certified by peer review) is the author/funder, who has granted bioRxiv a license to display the preprint in perpetuity. It is made available under aCC-BY-NC-ND 4.0 International license.

Harrington et al. Iron and zinc biofortification of wheat.

15. Velu G, Ortiz-Monasterio I, Cakmak I, Hao Y, Singh RP. Biofortification strategies to increase grain zinc and iron concentrations in wheat. J Cereal Sci. 2014;59(3):365-72.

16. Velu G, Singh RP, Crespo-Herrera L, Juliana P, Dreisigacker S, Valluru R, et al. Genetic dissection of grain zinc concentration in spring wheat for mainstreaming biofortification in CIMMYT wheat breeding. Sci Rep. 2018;8(1):13526.

17. Khokhar JS, Sareen S, Tyagi BS, Singh G, Wilson L, King IP, et al. Variation in grain Zn concentration, and the grain ionome, in field-grown Indian wheat. PLoS One. 2018;13(1):e0192026.

18. Monasterio I, Graham RD. Breeding for trace minerals in wheat. Food Nutr Bull. 2000;21(4):392-6.

19. Uauy C, Distelfeld A, Fahima T, Blechl A, Dubcovsky J. A NAC Gene regulating senescence improves grain protein, zinc, and iron content in wheat. Science. 2006;314(5803):1298-301.

20. Distelfeld A, Cakmak I, Peleg Z, Ozturk L, Yazici AM, Budak H, et al. Multiple QTL-effects of wheat Gpc-B1 locus on grain protein and micronutrient concentrations. Physiol Plantarum. 2007;129(3):635-43.

21. Zhao FJ, Su YH, Dunham SJ, Rakszegi M, Bedo Z, McGrath SP, et al. Variation in mineral micronutrient concentrations in grain of wheat lines of diverse origin. J Cereal Sci. 2009;49(2):290-5.

22. Borrill P, Connorton J, Balk J, Miller T, Sanders D, Uauy C. Biofortification of wheat grain with iron and zinc: integrating novel genomic resources and knowledge from model crops. Front Plant Sci. 2014;5(53).

23. Connorton JM, Balk J, Rodríguez-Celma J. Iron homeostasis in plants - a brief overview. Metallomics. 2017;9(7):813-23.

24. Johnson AA, Kyriacou B, Callahan DL, Carruthers L, Stangoulis J, Lombi E, et al. Constitutive overexpression of the OSNAS gene family reveals single-gene strategies for effective iron- and zinc-biofortification of rice endosperm. PLoS One. 2011;6(9):e24476.

25. Lee S, Jeon US, Lee SJ, Kim YK, Persson DP, Husted S, et al. Iron fortification of rice seeds through activation of the nicotianamine synthase gene. Proc Natl Acad Sci. 2009;106(51):22014-9.

26. Lee S, Persson DP, Hansen TH, Husted S, Schjoerring JK, Kim YS, et al. Bio-available zinc in rice seeds is increased by activation tagging of nicotianamine synthase. Plant Biotechnol J. 2011;9(8):865-73.

27. Usuda K, Wada Y, Ishimaru Y, Kobayashi T, Takahashi M, Nakanishi H, et al. Genetically engineered rice containing larger amounts of nicotianamine to enhance the antihypertensive effect. Plant Biotechnol J. 2009;7(1):87-95.

28. Goto F, Yoshihara T, Shigemoto N, Toki S, Takaiwa F. Iron fortification of rice seed by the soybean ferritin gene. Nat Biotechnol. 1999;17(3):282-6.

29. Søren B. Wheat ferritins: Improving the iron content of the wheat grain. J Cereal Sci. 2012;v. 56(no. 2):pp. 204-13-2012 v.56 no.2.

30. Singh SP, Keller B, Gruissem W, Bhullar NK. Rice NICOTIANAMINE SYNTHASE 2 expression improves dietary iron and zinc levels in wheat. Theor Appl Genet. 2017;130(2):283-92.

31. Neal AL, Geraki K, Borg S, Quinn P, Mosselmans JF, Brinch-Pedersen H, et al. Iron and zinc complexation in wild-type and ferritin-expressing wheat grain: implications for mineral transport into developing grain. J Biol Inorg Chem. 2013;18(5):557-70.

32. Beasley JT, Bonneau JP, Moreno-Moyano LT, Callahan DL, Howell KS, Tako E, et al. Multi-year field evaluation of nicotianamine biofortified bread wheat. Plant J. 2021.

33. Connorton JM, Jones ER, Rodríguez-Ramiro I, Fairweather-Tait S, Uauy C, Balk J. Wheat vacuolar iron transporter TaVIT2 transports Fe and $\mathrm{Mn}$ and is effective for biofortification. Plant Physiol. 2017;174(4):2434-44.

34. Sheraz S, Wan Y, Venter E, Verma SK, Xiong Q, Waites J, et al. Subcellular dynamics studies of iron reveal how tissue-specific distribution patterns are established in developing wheat grains. New Phytol. 2021;231(4):1644-57.

35. Beasley JT, Bonneau JP, Sanchez-Palacios JT, Moreno-Moyano LT, Callahan DL, Tako E, et al. Metabolic engineering of bread wheat improves grain iron concentration and bioavailability. Plant Biotechnol J. 2019;17(8):1514-26.

36. Banakar R, Alvarez Fernández Á, Abadía J, Capell T, Christou P. The expression of heterologous Fe (III) phytosiderophore transporter HVYS1 in rice increases Fe uptake, translocation and seed loading and excludes heavy metals by selective Fe transport. Plant Biotechnol J. 2017;15(4):423-32.

37. Fairweather-Tait S, Phillips I, Wortley G, Harvey L, Glahn R. The use of solubility, dialyzability, and Caco-2 cell methods to predict iron bioavailability. Int J Vitam Nutr Res. 2007;77(3):158-65.

38. Brodkorb A, Egger L, Alminger M, Alvito $P$, Assunção R, Ballance $S$, et al. INFOGEST static in vitro simulation of gastrointestinal food digestion. Nat Protocols. 2019;14(4):991-1014. 
bioRxiv preprint doi: https://doi.org/10.1101/2022.02.15.480518; this version posted February $18,2022$. The copyright holder for this preprint (which was not certified by peer review) is the author/funder, who has granted bioRxiv a license to display the preprint in perpetuity. It is made available under aCC-BY-NC-ND 4.0 International license.

Harrington et al. Iron and zinc biofortification of wheat.

39. Glahn RP, Lee OA, Yeung A, Goldman MI, Miller DD. Caco-2 Cell Ferritin Formation Predicts Nonradiolabeled Food Iron Availability in an In Vitro Digestion/Caco-2 Cell Culture Model. J Nutr. 1998;128(9):1555-61.

40. Lamacchia C, Shewry PR, Di Fonzo N, Forsyth JL, Harris N, Lazzeri PA, et al. Endosperm-specific activity of a storage protein gene promoter in transgenic wheat seed. J Exp Bot. 2001;52(355):243-50.

41. Yoo SY, Bomblies K, Yoo SK, Yang JW, Choi MS, Lee JS, et al. The 35S promoter used in a selectable marker gene of a plant transformation vector affects the expression of the transgene. Planta. 2005;221(4):523-30.

42. Bouis HE, Hotz C, McClafferty B, Meenakshi JV, Pfeiffer WH. Biofortification: a new tool to reduce micronutrient malnutrition. Food Nutr Bull. 2011;32(1 Suppl):S31-40.

43. Curtis MD, Grossniklaus U. A gateway cloning vector set for high-throughput functional analysis of genes in planta. Plant Physiol. 2003;133(2):462-9.

44. Christensen AH, Quail PH. Ubiquitin promoter-based vectors for high-level expression of selectable and/or screenable marker genes in monocotyledonous plants. Transgenic Res. 1996;5(3):213-8.

45. Hayta S, Smedley MA, Demir SU, Blundell R, Hinchliffe A, Atkinson N, et al. An efficient and reproducible Agrobacterium-mediated transformation method for hexaploid wheat (Triticum aestivum L.). Plant Methods. 2019;15(1):121.

46. Ishida Y, Tsunashima M, Hiei Y, Komari T. Wheat (Triticum aestivum L.) transformation using immature embryos. Methods Mol Biol. 2015;1223:189-98.

47. Watson A, Ghosh S, Williams MJ, Cuddy WS, Simmonds J, Rey M-D, et al. Speed breeding is a powerful tool to accelerate crop research and breeding. Nat Plants. 2018;4(1):23-9.

48. Minekus M, Alminger M, Alvito P, Ballance S, Bohn T, Bourlieu C, et al. A standardised static in vitro digestion method suitable for food - an international consensus. Food Funct. 2014;5(6):1113-24. 

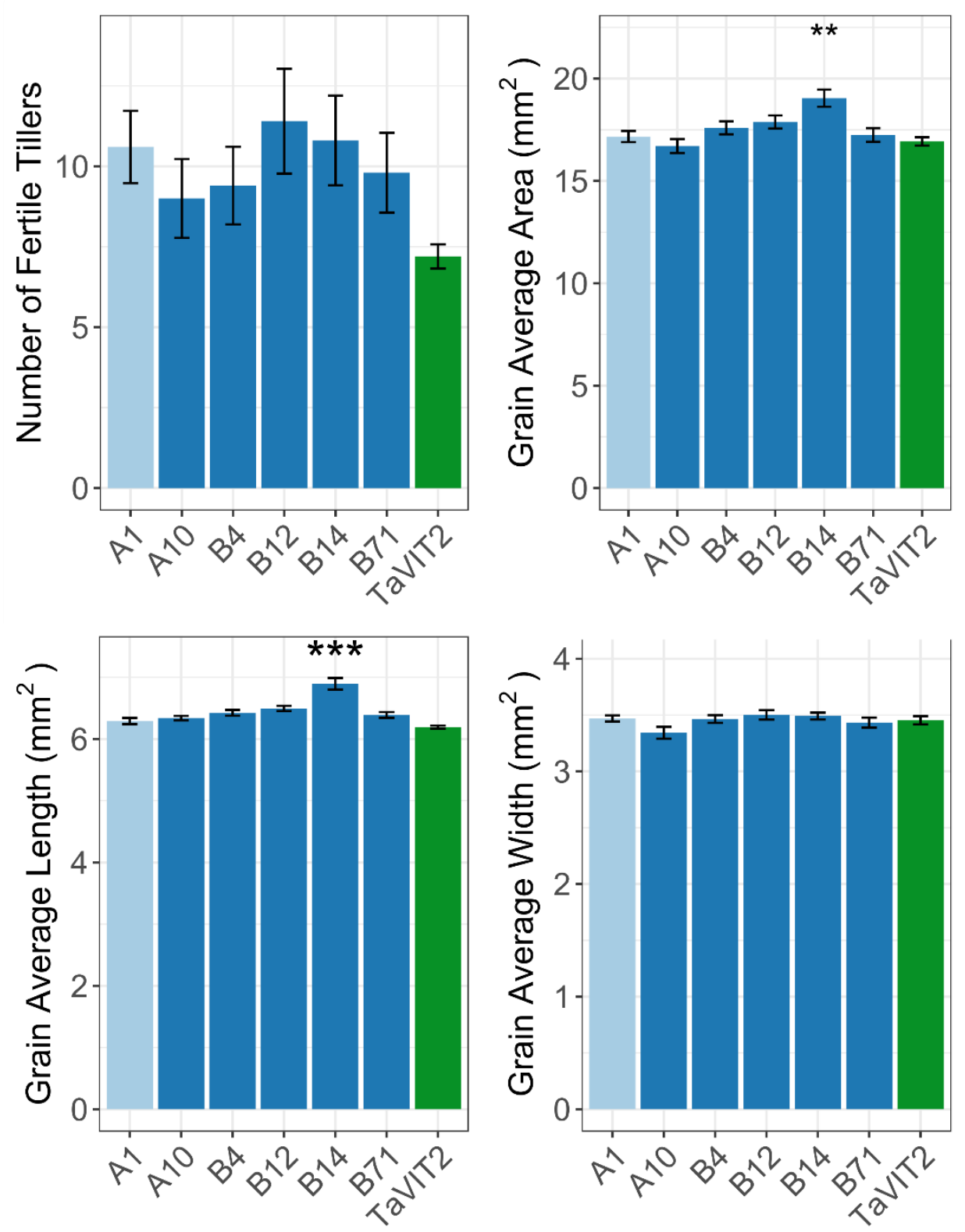

Supplemental Figure 1: The VIT-NAS construct does not affect plant growth in cv. Fielder. Fertile tiller number and grain size parameters (area, length, and width) in the null transformant (A1; light blue), VIT-NAS (A10, B4, B12, B14, B71; dark blue), and TaVIT2 (green) lines (** $p<0.01, * * * p<0.001$, Dunnett Test against A1). Error bars are the standard error of five biological replicates. 

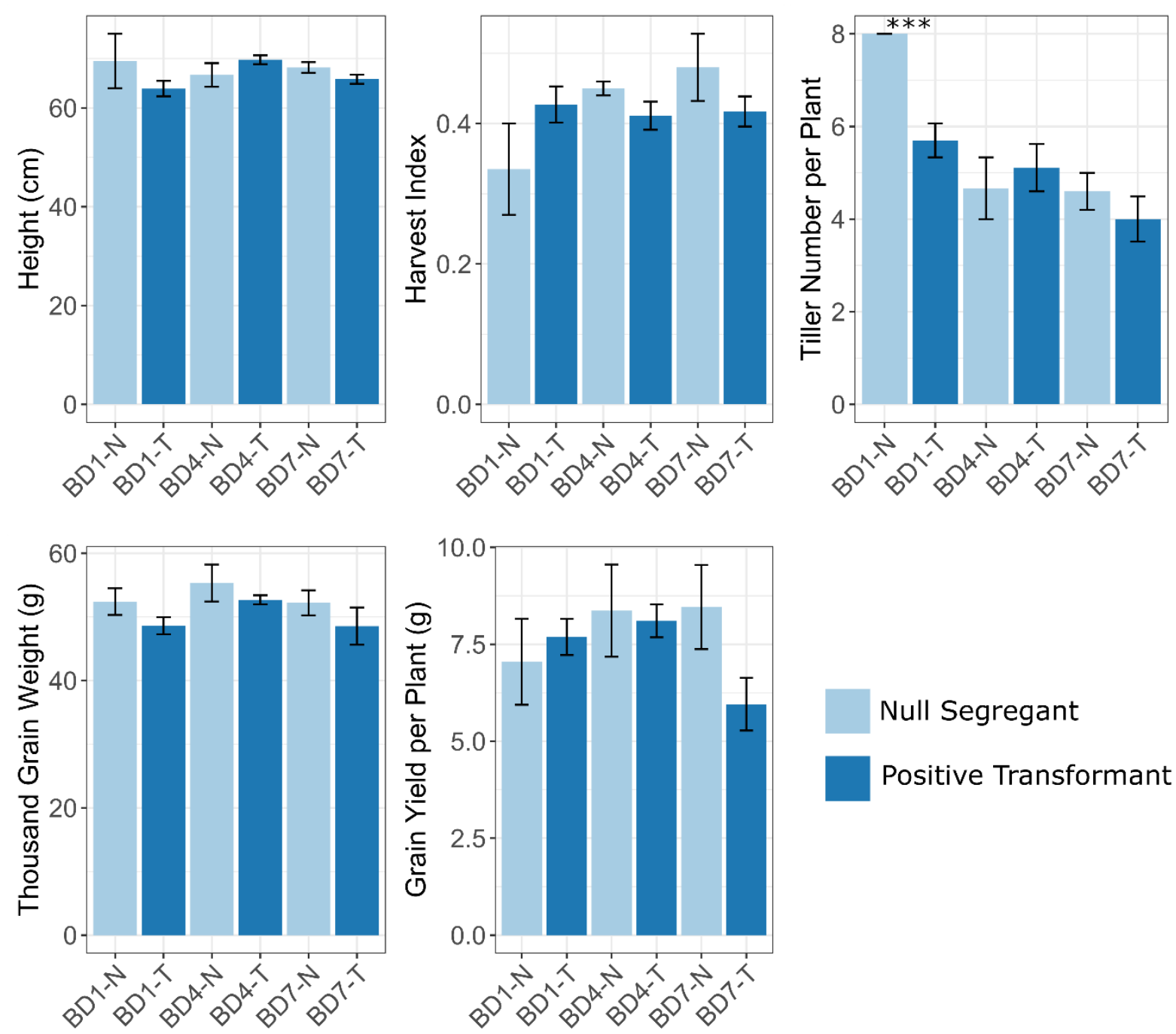

Null Segregant

Positive Transformant

Supplemental Figure 2: The VIT-NAS construct does not affect plant growth in cv. Gladius. Plant growth parameters including height, harvest index, tiller number, thousand grain weight, and grain yield per plant in three pairs of single-copy lines (dark blue, "-T") and their respective null segregant sibling (light blue, "-N). *** $p<0.001$, Student's t-test. Error bars are the standard error of the biological replicates; $n=2$ for BD1-N, 12 for BD1-T, 3 for BD4-N, 7 for BD4-T, 5 for BD7-N, and 7 for BD7-T. 

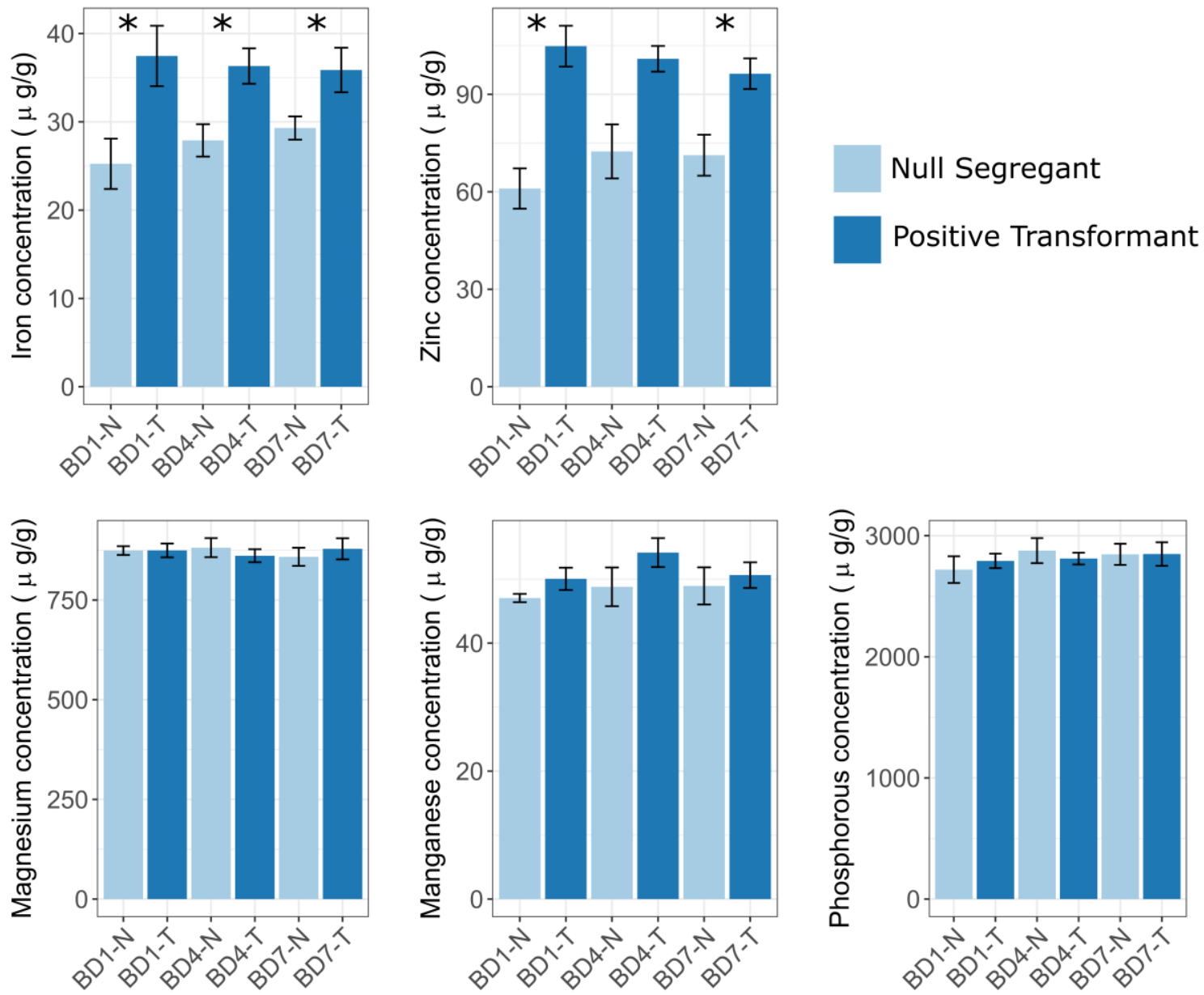

Supplemental Figure 3: The VIT-NAS lines in cv. Gladius have increased grain iron and zinc. Micronutrient levels in white flour for the cV. Gladius VIT-NAS lines, in three pairs of single-copy lines (dark blue, "-T") and their respective null segregant sibling (light blue, “-N). Error bars are the standard error of the biological replicates; $\mathrm{n}=2$ for BD1-N, 12 for BD1-T, 3 for BD4-N, 7 for BD4-T, 5 for BD7-N, and 7 for BD7-T. Student's ttest was carried out for each pair against the null segregant; ${ }^{*}, p<0.05,{ }^{* *}, p<0.01, * * *, p<0.001$. 

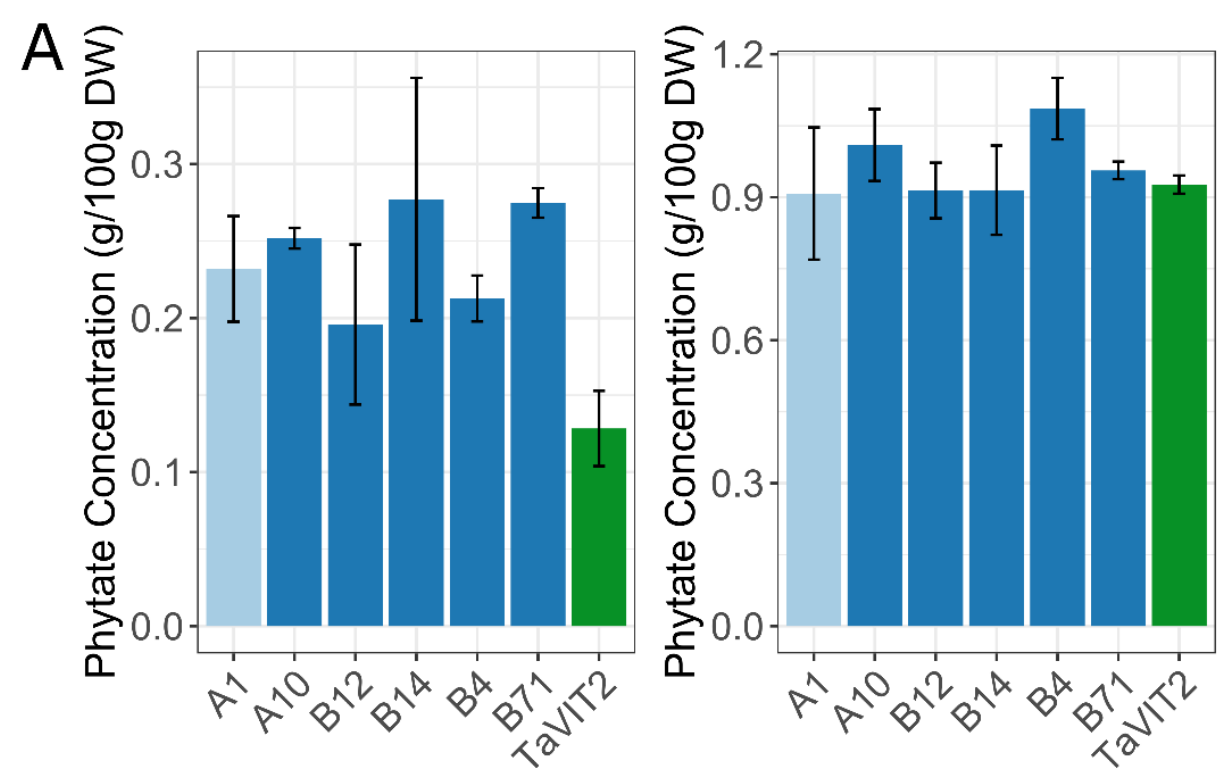

B
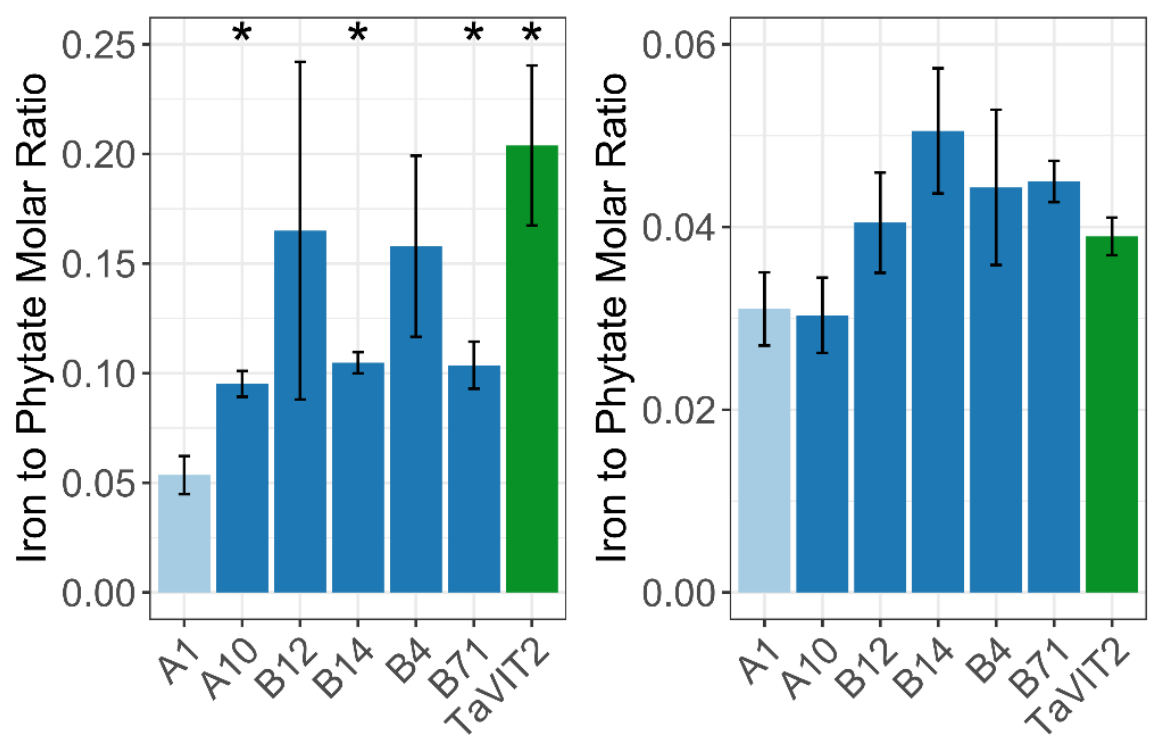

Supplemental Figure 4: Phytate levels in the cv. Fielder VIT-NAS lines are not increased. A, Phytate levels were measured in the white (left) and wholemeal (right) flour from the null transformant (A1; light blue), VITNAS (A10, B4, B12, B14, B71; dark blue), and TaVIT2 (green) lines. B, The ratio of iron to phytate in the white (left) and wholemeal (right) flour for the null transformant (A1; light blue), VIT-NAS (A10, B4, B12, B14, B71; dark blue), and TaVIT2 (green) lines. Error bars are the standard error of 3 biological replicates. $*, p<0.05, * *$, $\mathrm{p}<0.01, * * *, \mathrm{p}<0.001 ;$ Student's t-test against the null (A1). 


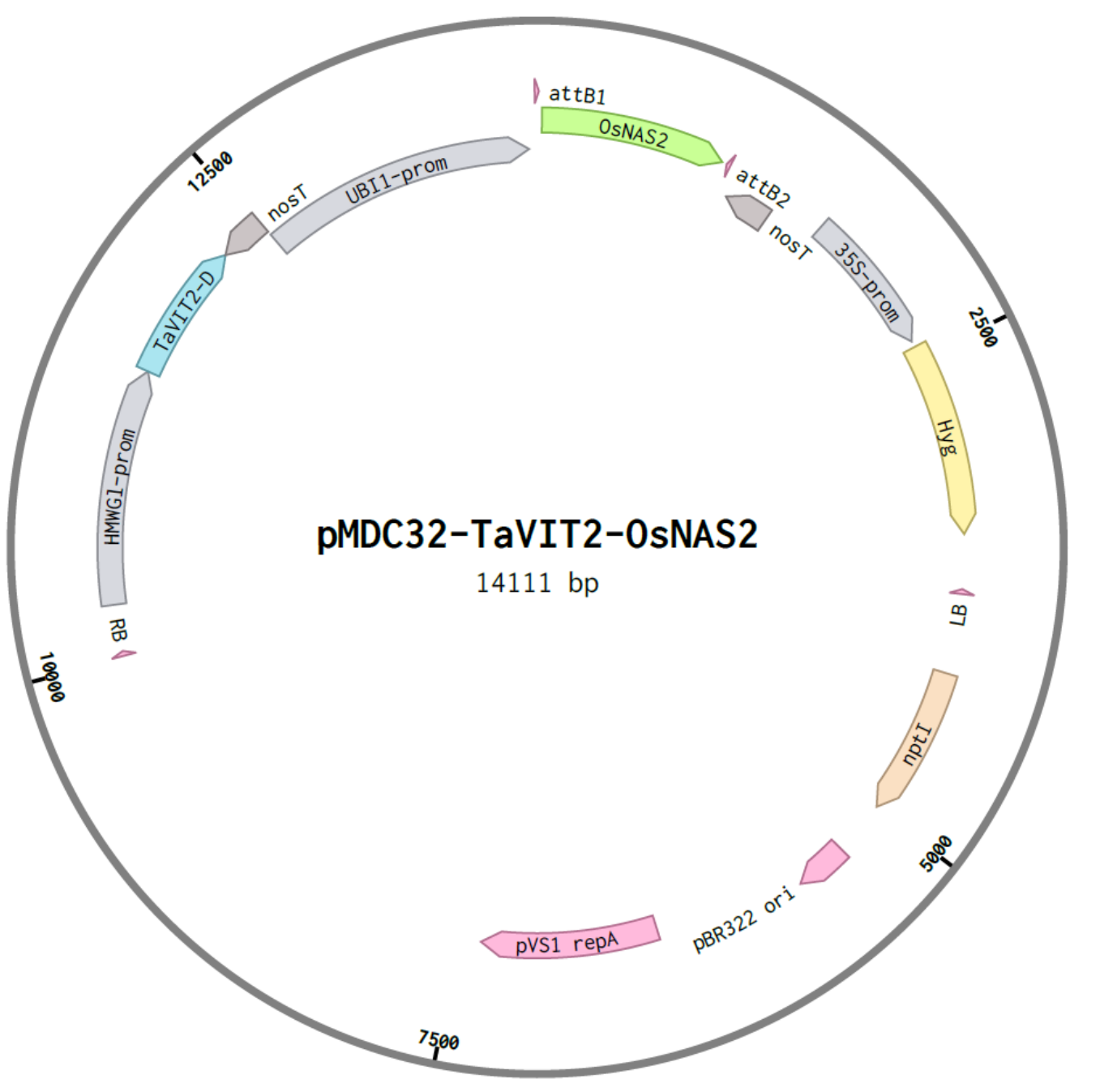

Supplemental Figure 5: T-DNA plasmid used for wheat transformation.

RB, Right Border of T-DNA; HMWG1-prom, promoter sequence of the High Molecular Weight GLUTENIN-D1 gene; TaVIT2-D, open reading frame of the VACUOLAR IRON TRANSPORTER 2, D homoeologue (TraesCS5B02G202100) from wheat; nosT, nopaline synthase terminator; UBI-prom, promoter sequence of the maize UBIQUITIN1 gene; attB1 and attB2, sequence elements (25 nt) for Gateway cloning; OsNAS2, open reading frame of the NICOTIANAMINE SYNTHASE 2 gene (Os03g0307200) from rice; 35S-prom, promoter sequence of the Cauliflower Mosaic Virus; Hyg, open reading frame of the plant selectable marker hygromycin phosphotransferase; LB, Left Border of T-DNA; $n p t l$, open reading frame of the bacterial selectable marker neomycin phosphotransferase; pBR322 ori, origin of replication for plasmids in Escherichia coli; $p V S$ repA, one of the genes for replication and stability of the plasmid in Agrobacterium tumefaciens (not all genes of the replicon are depicted). 
Supplemental Table 1: Primers used in this study.

The JC172 / JC173 primer pair was used to PCR-amplify the HMWG::TaVIT2 cassette and then insert this into the HindIII site upstream of ZmUBI1::OsNAS2 using In-Fusion cloning, see diagram in Fig. 1A. The OsNAS, TaVIT, and TaACTIN primer pairs were used to determine the expression levels in Fig. 1B. The Gladius primer pair was used for genotyping of the VIT-NAS cv. Gladius lines.

\begin{tabular}{|c|c|c|c|}
\hline Primer Name & Sequence & Efficiency & Source \\
\hline JC172 & $\begin{array}{l}\text { GGCCAGTGCCAAGCTCGAAATATGCAACA } \\
\text { TAATTTCC }\end{array}$ & NA & This paper \\
\hline JC173 & $\begin{array}{l}\text { GCAGGCATGCAAGCTCAGTAACATAGATG } \\
\text { ACACCG }\end{array}$ & NA & This paper \\
\hline OsNAS_F & GTTCCAGAAGGCGGAAGAGT & \multirow{2}{*}{$113 \%$} & \multirow{2}{*}{ This paper } \\
\hline OsNAS_R & AACGATCGGGGAAATTCG & & \\
\hline TaVIT_F & AGCGCCATGATGACCTCC & \multirow{2}{*}{$110 \%$} & \multirow{2}{*}{ This paper } \\
\hline TaVIT_R & CGGCAACAGGATTCAATCTTAAG & & \\
\hline TaACTIN_F & ACCTTCAGTTGCCCAGCAAT & \multirow{2}{*}{$99 \%$} & \multirow{2}{*}{ Uauy et al. 2006} \\
\hline TaACTIN_R & CAGAGTCGAGCACAATACCAGTTG & & \\
\hline Gladius_F & TTTCTTCGGCTACGTCAAGG & \multirow{2}{*}{ NA } & \multirow[t]{2}{*}{ This paper } \\
\hline Gladius_R & AAGACCGGCAACAGGATTC & & \\
\hline
\end{tabular}

